\title{
Insurability in Microinsurance Markets: An Analysis of Problems and Potential Solutions
}

\author{
Christian Biener and Martin Eling \\ Institute of Insurance Science, University of Ulm, Helmholtzstrasse 18, Ulm 89081, Germany. \\ E-mail: christian.biener@uni-ulm.de
}

This paper provides a comprehensive analysis of the insurability of risks in microinsurance markets. Our aim is to enhance the understanding of impediments to and facilitators of microinsurance from an economic perspective and outline potential solutions. The motivation for conducting this analysis arises from two important aspects. (1) Despite strong growth of microinsurance markets in recent years, more than 90 per cent of the poor population in developing countries have limited or no access to insurance. (2) Industry practitioners frequently highlight problems in the insurability of risks that hinder the development of microinsurance. We review 131 papers and find that the most severe problems stem from insufficient resources for risk evaluation, small size of insurance groups, information asymmetries and the size of the insurance premium. On the basis of the analysis, we discuss a number of potential solutions such as, for example, a cooperative microinsurance architecture.

The Geneva Papers (2012) 37, 77-107. doi:10.1057/gpp.2011.29

Keywords: microinsurance; insurability; moral hazard; adverse selection

\section{Introduction}

The aim of this paper is to conduct a systematic analysis of the insurability of risks in microinsurance markets, point out critical aspects that hinder their development and outline potential solutions to problems in these markets. Microinsurance is commonly defined as a financial arrangement intended to protect low-income people against specific perils in exchange for regular premium payments proportionate to the likelihood and cost of the risk involved. ${ }^{1}$ The microinsurance industry has seen strong growth in recent years, with average annual growth rates of approximately 10 per cent. ${ }^{2}$ Industry practitioners, however, estimate that only 5 per cent of the potential market is covered, and that there is a high degree of variability in terms of risk and geographical coverage, leaving large segments of the world's poor population with limited or no access to insurance. ${ }^{3}$

\footnotetext{
${ }^{1}$ See Churchill (2007). There exist two widespread definitions of microinsurance. Churchill (2007) refers to microinsurance as insurance for low-income people. Dror and Jacquier (1999) define microinsurance as financially autonomous schemes operating at the local level. Throughout this paper, we refer to the definition by Churchill (2007), but also integrate the aspect that microinsurance is typically operated in small locally focused insurance schemes.

${ }^{2}$ See Lloyd's and Microinsurance Centre (2009).

${ }^{3}$ See Roth et al. (2007).
} 
Providing insurance in developing countries is subject to a large array of problems, many of which are frequently addressed in practitioner studies. ${ }^{4}$ These studies reveal numerous problems with insurability, including moral hazard, adverse selection, correlated risks, high transaction costs and lack of data, making microinsurance challenging from an economic perspective. Whereas insurability is relevant in all insurance markets, the crucial question in the case of microinsurance is why these issues lead to the low market coverage and market failures that we often observe. In other words, which characteristics of the risks, the markets and the society obstruct the provision of financial arrangements to transfer risks through insurance mechanisms?

Despite the growing public interest in microinsurance, limited academic attention has been focused on this market to date. Churchill et al. provide an introduction to the relevance of compliance with insurability criteria, but do not indicate whether the required conditions are met for microinsurance. ${ }^{5}$ Vaté and Dror define the concept of insurability as a way of differentiating between health risks that can be insured and those that cannot. ${ }^{6}$ None of the existing studies provides a systematic analysis of the fundamental problems in microinsurance markets. In this paper, we systematically analyse a comprehensive set of studies on microinsurance with the aim of identifying problems in the insurability of risks. For this purpose, we utilise a set of nine fundamental insurability criteria proposed by Berliner. ${ }^{7}$ The idea is to synthesise current knowledge on insurability in microinsurance markets in a structured process, identify the most significant problems, and relate these to traditional and non-traditional solutions discussed in the academic literature and in the context of microinsurance. The key contribution of this paper is thus to enhance the transparency of problems, outline potential solutions and provide guidance to policymakers, regulators, microinsurance practitioners and development organisations in this developing field.

Our results show significant differences in the relevance of the nine insurability criteria. The most severe insurability problems stem from the stochasticity and quantification of risks, moral hazard and adverse selection issues, and the size of the insurance premium. There seem to be insufficient resources to control for problems arising from information asymmetries, ${ }^{8}$ as well as those due to a lack of data, ${ }^{9}$ undersized risk pools ${ }^{10}$ and excessive transaction costs. ${ }^{11}$ Health and agricultural insurance are the two types most affected by insurability problems. Many solutions, including index-based insurance, ${ }^{11}$ the use of self-control mechanisms, ${ }^{12}$ innovation in technology ${ }^{2}$ and reinsurance ${ }^{13}$ are discussed in the literature, but have yet to be proven

\footnotetext{
${ }^{4}$ See Levin and Reinhard (2007); Radermacher et al. (2009).

${ }^{5}$ See Churchill et al. (2003).

${ }^{6}$ See Vaté and Dror (2002).

${ }^{7}$ See Berliner (1982).

${ }^{8}$ See Churchill (2007).

${ }^{9}$ See Levin and Reinhard (2007).

${ }^{10}$ See Jütting (2004).

${ }^{11}$ See Linnerooth-Bayer et al. (2009).

12 See Dror and Jacquier (1999).

${ }^{13}$ See Bonnevay et al. (2002); Morduch (2006).
} 
successful. For example, a cooperative microinsurance architecture might combine the advantages of local arrangements with the capacity of a larger parent organisation.

The remainder of this paper is structured as follows. The next section provides a brief overview of microinsurance markets, including lines of business, organisational forms and distribution channels. In the section after that we introduce the insurability criteria that we use in the subsequent section to analyse pervasive problems in microinsurance markets. A discussion of potential solutions is presented in the penultimate section. The last section concludes and outlines options for future research.

\section{Microinsurance}

Microinsurance is based on the same principles as regular insurance. But despite similar risk coverage, insurance products and their relevance are different, whether they are in regular insurance or microinsurance. Simply downsizing regular insurance products is not an efficient way of approaching this low-income environment, which is what many first-movers in the marketplace did. It is far more effective to design specific products for this market, based on a deep understanding of the particular needs of the customers. ${ }^{14}$

Microinsurers underwrite a wide range of risks, including most lines of traditional insurance. The relative importance of these products is, however, quite different in microinsurance markets. We also find a huge gap between the demand and supply sides of this market. Death and illness are the most frequently identified risks for which people demand coverage. ${ }^{15}$ The impact of health risks on economic activity is especially severe and a major reason for persisting poverty in developing countries. ${ }^{16}$ Agricultural and catastrophe coverage are the most important non-life insurance products. This is not surprising given that agriculture exhibits the largest share in economic activity in most developing countries ${ }^{17}$ and that risks resulting in high agricultural losses contribute a great deal to the problem of persistent poverty. ${ }^{11}$ But although the demand for life, health and agricultural insurance products is high, the supply side faces several constraints, accounting for the small size of the market. Aggregate statistics show that health insurance plays a minor role in microinsurance markets and is available for only approximately 3 per cent of the population in the poorest countries. ${ }^{3}$ Life insurance is much more widely available. Overall, 40 per cent of the total policies in microinsurance are related to life insurance, the remaining 60 per cent are equally distributed between health, disability and property insurance. ${ }^{3}$ The high percentage for life insurance is mainly driven by credit life insurance policies, which are often sold as a bundle with microcredit products.

\footnotetext{
${ }^{14}$ See, for example, Churchill (2007); Dror et al. (2007).

15 See, for example, Cohen and Sebstad (2005).

${ }^{16}$ See Asfaw and Jütting (2007).

${ }^{17}$ See Levin and Reinhard (2007); Mills (2005).
} 


\section{Insurability of risks}

Berliner introduces nine criteria for differentiating between insurable and uninsurable risks. ${ }^{7}$ Due to its simple, but stringent and comprehensive approach, Berliner's set of insurability criteria is quite popular in the literature. Many authors utilise these or similar criteria to analyse insurance markets and products, ${ }^{18}$ for example, recent studies analyse emerging risks such as terror or climate risks. ${ }^{19}$ The nine criteria are sorted into three categories that classify risks in terms of actuarial, market and societal conditions (see Table 1). ${ }^{20}$

To be insurable in actuarial terms, loss exposures must be independent and loss probabilities should be estimated reliably, the maximum possible loss per event must be manageable in terms of insurer solvency, the average loss amount per event must be moderate, loss exposure must be sufficiently large, and the potential problems resulting from information asymmetry cannot be excessive. The actuarial criteria include, among others, the most important principle in insurance economics - the law of large numbers. This law implies that the larger the number of mutually independent risks in a risk pool, the lower the variance of mean losses.

The insurability conditions for the market are satisfied if the insurance premium is adequate to provide cost recovery, is affordable by the target population and the policy's cover limits are acceptable. An appropriate insurance premium includes the pure risk premium (to cover expected losses), safety loadings for process (to account for fluctuations of expected losses) and parameter risk (to account for the uncertainty in the estimation), and an expense loading. Cover limits are important since the insurer needs to achieve a certain security level and, at the same time, provide a valuable product.

With regard to the necessary societal conditions, coverage must be consistent with public policy and societal values, and with the legal restrictions governing coverage. Compliance with the public policy criterion includes restraints on offering insurance

${ }^{18}$ See, for example, Doherty (1991); Jaffee and Russell (1997); Janssen (2000); Karten (1997); Miranda and Glauber (1997); Nierhaus (1986); Schmit (1986); Vermaat (1995).

${ }^{19}$ See Charpentier (2008); Herweijer et al. (2009); Kunreuther and Michel-Kerjan (2004).

${ }^{20}$ We adapt the existing criteria catalogue to better fit microinsurance markets. We use a different definition of Criterion 4 (loss exposure). Berliner (1982) defines as a necessary condition for insurability that the expected loss frequency needs to be high for a risk to be insurable, not necessarily that there be a large number of risks in a portfolio. In contrast, we argue that it is the size of the risk pool (loss exposure) that is a necessary precondition for insurability, since the probability of loss for any given exposure is not affected by the actual experience of loss to another if we assume independence. Furthermore, high frequency losses generally are not easily insurable because the transaction costs of adjusting and paying those losses end up making the premium greater than the benefit in return. The original requirement by Berliner (1982) for Criterion 6 (insurance premium) is that a sufficient return on capital should be provided. However, sufficient return on capital does not mean to maximise returns. Instead, coverage of all relevant costs (claims costs, administrative costs and capital costs) is desirable to maintain the risk of insolvency at a reasonable level. See Vaté and Dror (2002) for a discussion. One aspect that is not addressed by Berliner (1982) is the availability of insured services to the target population, which is of particular relevance in microinsurance markets. Insuring risks for which services are not available (e.g., health services) would not be in line with the public policy criterion. We added this aspect to Criterion 8 (public policy). 
Table 1 Insurability criteria and related requirements according to Berliner

\begin{tabular}{|c|c|c|}
\hline \multicolumn{2}{|c|}{ Insurability criteria } & Requirements \\
\hline \multicolumn{2}{|c|}{ Actuarial (1) Randomness of loss occurrence } & Independence and predictability of loss exposures \\
\hline & (2) Maximum possible loss & Manageable \\
\hline & (3) Average loss per event & Moderate \\
\hline & (4) Loss exposure & Loss exposure must be large \\
\hline & (5) Information asymmetry & Moral hazard and adverse selection not excessive \\
\hline \multirow[t]{2}{*}{ Market } & (6) Insurance premium & Cost recovery and affordable \\
\hline & (7) Cover limits & Acceptable \\
\hline \multirow[t]{2}{*}{ Societal } & (8) Public policy & Consistent with societal values and availability of services \\
\hline & (9) Legal restrictions & Allow the coverage \\
\hline
\end{tabular}

for trivial risks or risks for which no need for insurance exists and setting incentives for criminal actions. Legal restrictions include limits on the activities an insurance company is permitted to engage in and prohibitions against insuring certain risks. Stability in the legal framework of a particular country is another condition that must be met. ${ }^{21}$

\section{Insurability in microinsurance markets}

We review studies on microinsurance covering the period from 1999 to early 2011 in order to identify all relevant references to insurability issues. To capture all relevant references and to assure that only studies meeting academic quality standards are included in the survey, we follow a strict search and selection strategy (a detailed description of the search strategy is available upon request). This strategy resulted in a review of 131 peer-reviewed journal articles, 89 of which discuss problems in the insurability of risks in microinsurance markets.

The studies focus on Africa and Asia. Only two studies refer to Latin America (see Table 2, Panel A). The review reveals a high interest in the topic of microinsurance in recent years (Panel B), but we also observe that the largest share of publications are found in journals on health and development economics, whereas there is little research on microinsurance in the area of risk management and insurance (Panel C).

${ }^{21}$ It is necessary to question this set of criteria in light of microinsurance markets, since the criteria were developed for traditional insurance markets. In particular, the insurability criteria can be enhanced to better meet the environment in which microinsurance operates. Establishing a completely new set of criteria is, however, beyond the scope of this paper. We, thus, utilise the nine insurability criteria in this paper, but highlight aspects that need to be considered more closely in the case of microinsurance. An example is that aspects, such as education and infrastructure, are not sufficiently covered by the traditional insurability criteria. 
Table 2 Distribution of publications and relevance of insurability criteria

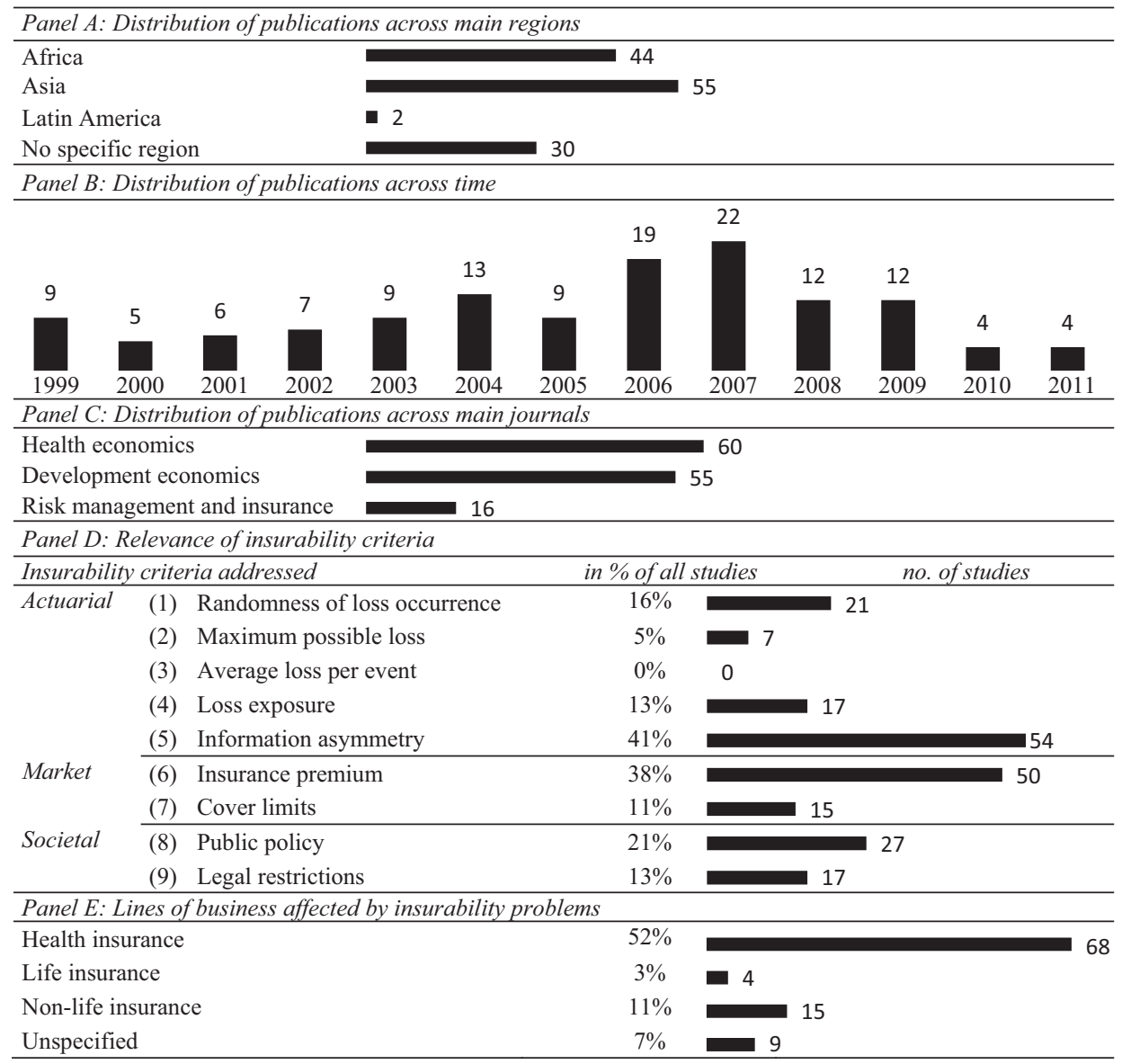

Note: Some references refer to multiple insurability criteria and lines of business. Thus the number of studies for all insurability categories and lines of business does not equal the number of studies considered in the analysis. The number of studies reviewed in the analysis is 131 .

In Panel D of Table 2, we aggregate the findings so as to draw generalised conclusions as to the most significant problems of insurability. ${ }^{22}$ The results show significant differences in the relevance of the nine criteria. The major impediments to

${ }^{22}$ The derivation of the significance of specific problems is based on the number of articles providing evidence of problems with respect to the insurability criteria and lines of business. A limitation of this approach is that issues raised in published articles primarily reflect prevailing knowledge; this might not necessarily correspond with the most significant problems. However, an advantage of this approach is that it provides an objective basis to derive problems relevant to the industry. Furthermore, we include a wide variety of articles from different fields to provide insights from a variety of perspectives. 
insurability of risks stem from information asymmetry and the insurance premium. Less dominant but nevertheless essential in the provision of microinsurance are public policy, randomness of loss occurrence, loss exposure and legal restrictions. Maximum possible loss and cover limits are referred to less frequently. We find no study addressing average loss per event. Panel $\mathrm{E}$ sets out the decomposition of the findings as to the primary lines of business affected by insurability problems. The health insurance and non-life insurance lines are thus more often the subject of discussions about insurability problems.

Finding solutions to the problems arising in these lines of business could be of enormous benefit in designing sustainable business models, for economic development, ${ }^{23}$ and for addressing persistent poverty. ${ }^{24}$ Although life insurance products have by far the largest market share in developing countries, ${ }^{3}$ there are only four studies discussing problems in the insurability of life risks. This result might suggest that this type of insurance is relatively easy to provide, underlining the relevance of complying with fundamentals of insurability. This finding may also indicate an opportunity to transfer successful approaches from life microinsurance to other lines of business. The provision of life microinsurance products is often tied to existing distribution channels of microfinance institutions. Selling these products together is a way to reduce transaction costs and the problems of adverse selection, and to reach a large audience, making the line easier to sell and thus achieve economies of scale. As such, linking insurance to activities of microfinance institutions can be attractive for other lines of business. Joint product distribution of health insurance through microfinance institutions has already proven successful and indicates that the industry is able to provide innovative solutions. $^{25}$

We next discuss each of the insurability criteria and provide key findings for each line of business. A more detailed list of all studies and their assignment to criteria and lines of business are provided in the Appendix.

\section{Randomness of loss occurrence}

A large array of problems in insuring risks in developing countries stems from violation of requirements intrinsic to the entire concept of insurance, that is, independence of risks and the quantification of loss probabilities. Problems frequently addressed relate to data availability, covariant risks and increasing variability in loss frequency and/or loss severity, among others.

The findings for health insurance involve two essential domains: data availability and covariant risks. Data availability is a serious issue for health insurers; they are

\footnotetext{
${ }^{23}$ See Arena (2008) for a discussion of the link between insurance market development and economic growth.

${ }^{24}$ See, for example, Asfaw and Jütting (2007) for health risks and Linnerooth-Bayer et al. (2009) for catastrophe risk.

${ }^{25}$ The self-employed women association and UpLift India utilise the integration of microfinance and microinsurance activities in India (Acharya and Ranson, 2005; Dror et al., 2009a).
} 
often reported as lacking even the most basic data on their business. ${ }^{26}$ Cohen and Sebstad address the unpredictability of health risks in developing countries, especially those involving long-term illness such as HIV/AIDS. ${ }^{15}$ Dror et al. illustrate that sufficient data on health cost in India is not available. ${ }^{27}$ The increasing penetration of these risks, as well as their unpredictability due to lack of reliable data, makes calculating an actuarially fair premium challenging. Premium loadings that account for uncertainty in the underlying risk are thus high, and cover limits are exceptionally low, making the coverage expensive and of questionable value. Covariant health risks, particularly epidemic-like diseases (e.g., malaria), have a strong impact on micro health insurance schemes that are typically small, regional and relatively homogeneous. $^{28}$

Life insurance products are generally believed to be easy to provide relative to other lines. There are, however, factors that can impact the insurability of risk. Cohen and Sebstad and Dercon et al. note that increasingly high HIV/AIDS rates in African countries and the related increase in mortality rates, especially in younger cohorts, cause serious problems. ${ }^{29}$ Particularly for burial societies and community-based insurance schemes, increasing mortality rates may dilute their financial stability and solvency, since many are small and poorly diversified.

The non-life insurance business is subject to many problems related to randomness requirements, especially regarding agricultural insurance. These problems originate in a lack of data, covariant risks and increasing variability in loss frequency and intensity. Francisco points out that the provision of coverage against risks resulting from climate change (droughts, storms, rising sea level) is constrained due to limited information on the underlying risks and contribute to market failure. ${ }^{30}$ This is also true for developed insurance markets, but it is, however, even more critical in developing countries. Complicating the problem of lack of historical data is the increasing variability in frequency and severity of catastrophic events, ${ }^{31}$ both of which result in high premium loadings for this type of insurance. ${ }^{32}$ Covariant risks are present in the non-life insurance business in developing countries and are a major cause of market failure. ${ }^{33}$ Those risks include droughts and floods that affect large areas at the same time, and quickly lead to crop losses. ${ }^{15}$ Covering covariant risks is problematic because the joint probabilities of incurring losses, especially for small entities, are high, thus requiring high premium loadings. $^{34}$

\footnotetext{
${ }^{26}$ See McCord (2007).

${ }^{27}$ See Dror et al. (2008).

${ }^{28}$ See Carrin et al. (2005); Dror and Jacquier (1999); Wiesmann and Jütting (2000).

${ }^{29}$ See Cohen and Sebstad (2005); Dercon et al. (2006).

${ }^{30}$ See Dlugolecki (2008); Francisco (2008); Linnerooth-Bayer and Mechler (2006); Smolka (2006).

${ }^{31}$ See Dlugolecki (2008); Francisco (2008); Linnerooth-Bayer et al. (2009); Linnerooth-Bayer et al. (2005).

${ }^{32}$ See Barnett and Mahul (2007).

${ }^{33}$ See Barnett et al. (2008).

${ }^{34}$ See Linnerooth-Bayer et al. (2005).
} 


\section{Maximum possible loss}

The maximum loss that could occur from a certain risk does not receive much coverage in the studies we analyse and is primarily discussed in the non-life context. Risks exhibiting maximum losses that exceed the capacity of a microinsurance scheme in terms of capital are considered uninsurable. These risks typically involve agriculture such as crop and livestock.

For health microinsurance, Hamid et al. state that micro health insurance schemes in Bangladesh have limited scope to cover large losses. ${ }^{35}$ A serious problem for the non-life business is insufficient financial capacity paired with low-frequency, high-severity risks. ${ }^{36}$ Highly skewed loss distributions are a significant risk to insurers' solvency, especially for small, local schemes. ${ }^{37}$ Linnerooth-Bayer and Mechler and MezeHausken et al. call for wider risk-sharing arrangements in the provision of insurance coverage against risks posed by increased climatic variability. ${ }^{38}$ The underlying argument is that an insurer's risk of insolvency in the case of low-frequency, high-severity events is high and demands further diversification of risks as well as risk mitigation.

\section{Average loss per event and loss exposure}

Average loss per event and loss exposure are closely related and are discussed jointly. The two criteria significantly determine whether insurance is an appropriate strategy for specific risks. According to our review, microinsurance markets are not affected by problems resulting from exceeding average losses; however, it is possible that this finding does not hold across all lines of business as data limitations inhibit the in-depth study of this issue. High expenses due to cost escalation in health insurance indicate that average benefits relative to premiums are too high to make insurance coverage viable. ${ }^{39}$ Average loss per event could thus be a relevant issue in the provision of health insurance. However, it might also be that insurance products are not appropriately tailored to the needs and willingness to pay.

Loss exposure has been the subject of more work, especially in the area of health insurance. Several studies note that risk pooling remains limited due to the small size of many microinsurance schemes and the consequent limited applicability of the law of large numbers. Dror and Armstrong explicitly show the effect of risk pool size on insurance premiums for micro health insurance schemes in a simulation study. The authors find that as scheme size decreases, exponentially increasing capital loadings are necessary to assure solvency. ${ }^{40}$ The financial instability and insolvency of small microinsurance schemes are frequently reported as problematic. ${ }^{41}$ Even though

\footnotetext{
${ }^{35}$ See Hamid et al. (2011).

${ }^{36}$ Per capita costs of natural disasters in relation to GDP are more than 20 times higher in developing countries; see Linnerooth-Bayer and Amendola (2000).

${ }^{37}$ See Chantarat et al. (2007); Giné et al. (2007).

${ }^{38}$ See Linnerooth-Bayer and Mechler (2006); Meze-Hausken et al. (2009).

${ }^{39}$ See, for example, Desmet et al. (1999); Devadasan et al. (2006); Ekman (2004); Poletti et al. (2007).

40 See Dror and Armstrong (2006).

${ }^{41}$ See Drechsler and Jütting (2007); Msuya et al. (2007); Obermann et al. (2006); Wagstaff and Lindelow (2008).
} 
scheme size is strongly related to financial stability, there is a trade-off between size and decentralisation. Increasing size and/or centralisation may put at risk much of the cost efficiency and avoidance of information asymmetries that are great advantages of operating locally in terms of contract design, enforcement and delivery. ${ }^{42}$

For life insurance, Dercon et al. report that funeral insurance risk pools in Ethiopia and Tanzania are usually small and local in nature such that risk pooling remains limited. ${ }^{43}$ As found for health insurance, there is a trade-off between size and the mitigation of information asymmetries in the life insurance business due to enforcement and information problems that arise in larger anonymous insurance schemes. ${ }^{44}$

Non-life insurance is affected by two major problems: low-frequency, high-severity risks and small risk pools. Chantarat et al. illustrate for weather-related catastrophes in Kenya that local insurance schemes are highly vulnerable to losses from lowfrequency, high-severity events. ${ }^{45}$ Giné et al. note for the Indian rainfall insurance market that the small market size and subsequently small risk pools lead to sparse supply and high insurance premiums. ${ }^{46}$

\section{Information asymmetry}

Problems associated with information asymmetry are common to the insurance industry in general; however, they appear to be especially problematic for microinsurance. Accordingly, we find many studies addressing these problems. The largest share of studies addressing information asymmetries investigates health insurance, providing evidence of adverse selection, moral hazard and fraud. Adverse selection is a fundamental problem in health insurance as especially individuals with high future healthcare needs (e.g., chronically ill people, old people) are prone to purchase health insurance. ${ }^{47}$ For example, Zhang et al. report that age is positively related to willingness to join a health insurance scheme in China. ${ }^{48}$ Criel and Waelkens find that women joined a health insurance scheme in West Africa precisely because they are regularly ill. ${ }^{49}$ Pregnant women or women of childbearing age are found to have a higher probability of joining a health insurance scheme in Africa. ${ }^{50}$ The value of health insurance to an individual primarily results from risk reduction, which is complemented by the option of obtaining access to medical services. ${ }^{51}$ It is this complementary value that provides the rationale for an important differentiation regarding increasing utilisation rates. The higher probability of using medical services when one has health insurance may be ascribed to (1) taking care of health needs that

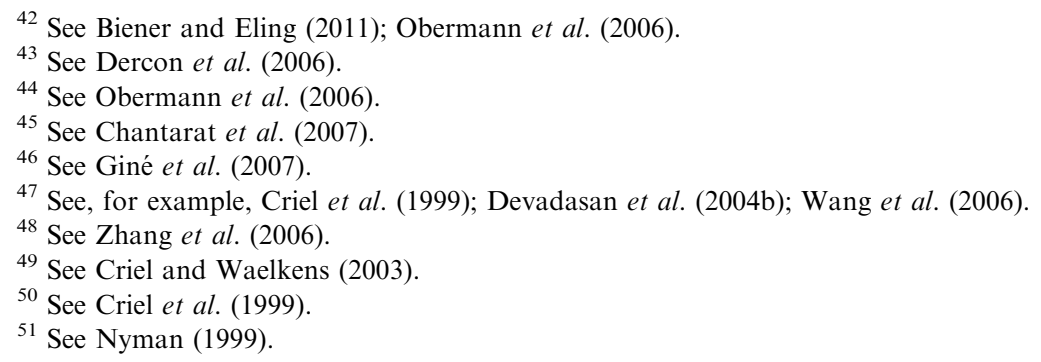


are not affordable in the absence of health insurance or (2) an overuse of not strictly necessary medical services. The first rationale is especially relevant for developing countries since unmet health needs tend to be substantial. ${ }^{52}$ In this regard, Dror et al. find that increased utilisation rates with insureds are not due to adverse selection and that microinsurance can alleviate the underutilisation of healthcare. ${ }^{53}$ The different reasons for increased utilisation rates are, however, not trivial. Our review reveals numerous issues related to overuse of medical services. ${ }^{15}$ This phenomenon is not restricted to policyholders, but also extends to providers of medical services. Sepehri et al. illustrate incentives for the excessive provision of services such as long hospital stays and overuse of diagnostics and drugs adjunct to health insurance in Vietnam. ${ }^{54}$ Similar observations are made for other regions. ${ }^{55}$ In addition to adverse selection and moral hazard, health insurance schemes face problems resulting from fraudulent behaviour by insureds. For instance, McCord and Osinde find that 30-40 per cent of healthcare costs are related to fraud for a health insurance scheme in Africa. ${ }^{56}$ Other studies find smaller but still significant values for fraud. ${ }^{57}$

In the case of life insurance, we find evidence of information asymmetries for funeral insurance and term life insurance. Bryant and Prohmmo and Dercon et al. find adverse selection as well as fraud for funeral insurance in Asia and Africa. ${ }^{58}$ Giesbert et al. find evidence for adverse selection in term life insurance in Ghana. ${ }^{59}$ Life insurance coverage is, however, not prey to moral hazard, which is not surprising as the event that triggers coverage - death - is a fairly transparent and completely inevitable occurrence, meaning that the beneficiary of the insurance contract has no informational advantage over the insurer.

Evidence of information asymmetries in non-life business is reported for agricultural and property insurance. Barnett et al. emphasise that information asymmetries are persistent in the U.S. agricultural insurance market but tend to be more severe in developing countries. ${ }^{33}$ In addition, the costs of strategies for addressing adverse selection, moral hazard and fraud relative to the small sums insured are higher in microinsurance markets, limiting the range of potential coping strategies. Crop and catastrophe insurance both exhibit patterns of information asymmetries, resulting in adverse selection, moral hazard and fraud. ${ }^{60}$ Furthermore, we find reference indicating that there is a high level of moral hazard in insuring against theft or fire of property that seriously restricts the provision of property insurance. ${ }^{15}$

\footnotetext{
${ }^{52}$ See Jowett et al. (2004).

${ }^{53}$ See Dror et al. $(2005,2009 a)$.

54 See Sepehri et al. (2006).

${ }^{55}$ See, for example, Acharya and Ranson (2005); Sapelli and Vial (2003); Wagstaff et al. (2009); Wiesmann and Jütting (2000).

${ }^{56}$ See McCord and Osinde (2005).

${ }^{57}$ See, for example, Drechsler and Jütting (2007); Obermann et al. (2006).

58 See Bryant and Prohmmo (2002); Dercon et al. (2006).

${ }^{59}$ See Giesbert et al. (2011).

${ }^{60}$ See, for example, Francisco (2008); Linnerooth-Bayer et al. (2009); see also Miranda and Glauber (1997).
} 


\section{Insurance premiums}

For all lines of business, we find that insurance premiums either are not sufficient to assure cost recovery or not affordable by the target population, or even both. Some of the problems in the provision of insurance coverage in developing countries are interrelated with this dilemma, such as premium loadings resulting from violations of insurability criteria, for example, limited historical data and covariant risks.

In health insurance, high premiums are due to high transaction costs and cost escalation. Loadings due to fluctuations of expected benefits and uncertainty in the estimation that we observe with regard to the criterion randomness of loss occurrence amplify this effect. Many authors find that high transaction costs, increasing healthcare costs and a higher than expected utilisation of health services are characteristic of microinsurance schemes, leading to increasing pure risk premiums. ${ }^{61}$ As to the demand side of the market, many studies investigating insurance premiums confirm that such premiums are not affordable by the target population; ${ }^{62}$ however, Dong et al. find that affordability in terms of willingness to pay is in line with the costs of providing health insurance when government subsidies in a community-based health insurance scheme are considered. ${ }^{63}$ Even more challenging from a policy perspective are results finding that premiums are both insufficient to cover costs and unaffordable for customers. ${ }^{64}$

Four studies in our literature review relate to life insurance, two of which consider high premiums as an impediment to funeral insurance provision. Cohen and Sebstad argue that life insurance products remain unaffordable for large parts of the very poor population. ${ }^{65}$ The small number of studies addressing pricing issues for life insurance is somewhat surprising as life insurance has by far the largest market share. ${ }^{3}$ The relative absence of work on this topic indicates that pricing life insurance products may not be much of a problem in the microinsurance industry.

Transaction and financing costs are found to be the primary drivers of high premiums in non-life. Dlugolecki explicitly states that transaction costs are the major reason for the failure of insurance markets covering climate risks. ${ }^{66}$ Many authors support this notion, indicating that insurance premiums are significantly larger than expected losses due to the high transaction and financing costs of microinsurance programmes. ${ }^{67}$ The concurrence of high transaction costs and high risk loadings are the major reason for unaffordable premiums and market failure also in catastrophe insurance. ${ }^{11}$

\footnotetext{
${ }^{61}$ See, for example, Acharya and Ranson (2005); Atim (1999); Carrin et al. (2005); Drechsler and Jütting (2007); Ensor (1999); Jütting (2004); McCord (2007); Pauly et al. (2006); Wiesmann and Jütting (2001).

${ }^{62}$ See, for example, Carrin et al. (2005); Chankova et al. (2008); Cohen and Sebstad (2005); Criel and Waelkens (2003); Devadasan et al. (2004b); Dror and Armstrong (2006); Ranson et al. (2007); Wang et al. (2006).

${ }^{63}$ See Dong et al. (2004).

${ }^{64} \mathrm{See}$, for example, Ekman (2004).

${ }^{65}$ See Bryant and Prohmmo (2002); Cohen and Sebstad (2005).

${ }^{66}$ See Dlugolecki (2008).

${ }^{67}$ See, for example, Giné et al. (2007); Linnerooth-Bayer et al. (2009); Patt et al. (2010).
} 
The analysis of cover limits is important since customers have little experience with professional insurance mechanisms. Discussion of this issue sheds light on the relationship between insurer and insured by revealing their different levels of acceptance of coverage limits. Divergence between the perceptions of cover limits may reveal an underlying misconception between the contracting parties that needs to be addressed. The insurer needs to achieve a certain level of protection when setting cover limits and, simultaneously, provide a valuable product. Cover limits encompass a large array of regulations necessary to protect the insurer from such issues as high frequencies of small losses and indemnities higher than incurred losses. These cover limits are challenging, if clients find those unacceptable or do not understand them.

The health systems of many developing countries are characterised by low-quality care, substandard infrastructure, high costs and a far from comprehensive coverage of the population. With respect to cover limits, we find exclusions of benefits from coverage by policy terms. These exclusions create a high level of financial risk for the insured because they may drop even farther below the poverty line due to treatment costs that are not covered, high deductibles and low ceilings. ${ }^{68}$ This leaves the insured with a small band of covered health services and exposure to a high level of financial risk. Furthermore, high deductibles may increase inequity, because the poorest segments cannot access health services. ${ }^{69}$

Our review reveals that the level of benefits provided by microinsurance schemes is too low to provide financial protection against health risks to the low-income population. This conclusion, however, must be viewed with some caution. Some studies report that cover limits are generally not accepted by the target population due to a lack of understanding regarding risk management strategies. ${ }^{70}$ For example, if some insurers exclude chronic illnesses from coverage, most people will not see this exclusion as justifiable, especially if they are suffering from a chronic illness. ${ }^{71}$ A challenge for microinsurance programmes is thus to develop products that provide protection for the insurer through cover limits that are both understood and accepted by the target population. Education and the involvement of the target population in product design will be key to this endeavour. ${ }^{72}$

${ }^{68}$ See, for example, Atim (1999); Bennett (2004); Chankova et al. (2008); Devadasan et al. (2007); Drechsler and Jütting (2007); Polonsky et al. (2009); Schneider and Hanson (2006); Sepehri et al. (2006); Wagstaff et al. (2009).

${ }^{69}$ See, for example, Dror et al. (2009a); Sinha et al. (2006).

${ }^{70}$ See, for example, Cohen et al. (2005).

${ }^{71}$ In many industrialised countries, including Germany and Switzerland, the problems of adverse selection are avoided by making health insurance compulsory for both good and bad risks in health insurance systems. This implies that the insurer has the obligation to enter into a contract with all types of risks and all insureds have to purchase the insurance. Chronic illnesses are fully covered.

${ }^{72}$ See, for example, Dror et al. (2007) for a discussion of the involvement of the target population in the design of micro health insurance products. 


\section{Public policy}

Meeting the public policy criterion requires that risk coverage be consistent with societal values. This means, for example, not insuring trivial risks and not providing any incentives for engaging in criminal acts (e.g., policies must state definitely that fire loss will not be covered if the fire was purposely set). Collective fairness should be preserved by avoiding cross-subsidisation between lines of business. A further aspect unaddressed in the work of Berliner, ${ }^{7}$ but of particular relevance in microinsurance markets, is the availability of insured services to the insured. Insuring risks for which services are not available (e.g., health services) would not be in line with the public policy criterion.

The findings for health insurance show that issues of public policy are of high importance. In particular, we find systematic medical cost inflation, as well as an absence of an insurance culture. In many regions, providing health insurance leads directly to provider-induced price increases for medical services. The emergence of insurance schemes encourages the overprovision of high-tech and medically unnecessary care, leading to significantly higher costs of treatment for insured patients. ${ }^{73}$ The absence of an insurance culture manifests itself in low levels of demand due to conflicts of interest between microinsurers and public goals, such as coverage of chronic illnesses, ${ }^{74}$ reluctance to engage in risk pooling that goes beyond traditional boundaries such as families, villages or ethnic groups, ${ }^{75}$ and a low degree of risk aversion and/or a misperception of risks. ${ }^{76}$ All these problems imply that addressing health risks using traditional insurance mechanisms may be at odds with societal values in some developing countries. Microinsurance schemes need to carefully review and address these issues in light of the country's societal and political values. ${ }^{44}$ A critical aspect in insuring health risks is the availability and quality of health services in microinsurance markets. In many countries, we find that people are reluctant to insure against health risks due to a lack of infrastructure (e.g., healthcare facilities are not available, costs to reach them are too high or the quality of treatment is low). ${ }^{77}$

Providing non-life insurance in developing countries may actually encourage criminal acts, for example, theft of insured property. ${ }^{15}$ It may lead to a crowding out or less humanitarian aid after a disaster ${ }^{78}$ and can decrease motivation for investing in precautionary measures. ${ }^{34}$ The problems associated with the lack of an insurance culture discussed above in relation to health insurance also exist to some extent in non-life insurance. ${ }^{79}$

\footnotetext{
${ }^{73}$ See Desmet et al. (1999); Devadasan et al. (2004a); Ekman (2007); Wagstaff and Lindelow (2008).

${ }^{74}$ See Devadasan et al. (2006).

${ }^{75}$ See Carrin (2002); Criel and Waelkens (2003).

${ }^{76}$ See Dong et al. (1999); Kiwara (2007); Pauly et al. (2006); Wiesmann and Jütting (2000).

${ }^{77}$ See Allegri et al. (2006); Carrin et al. (2005); Cohen and Sebstad (2005); Criel and Waelkens (2003); Dekker and Wilms (2010); Devadasan et al. (2004b); Ranson et al. (2006); Sinha et al. (2006).

${ }^{78}$ See Linnerooth-Bayer and Amendola (2000).

${ }^{79}$ See Linnerooth-Bayer et al. (2009); Linnerooth-Bayer and Mechler (2006).
} 


\section{Legal restrictions}

A country's laws and regulations applicable to the insurance business can have a great impact on the success of the microinsurance market. Legal restrictions include, among other things, limits on types of activities in which insurers are permitted to engage and prohibitions against insuring certain risks or particular forms of insurance schemes.

Tight regulation, regulation-induced transaction costs, limited enforcement of legal contracts and uncertainty as to the stability of the legal environment are problems that affect every line of business in the microinsurance industry. ${ }^{80}$ However, there are regulations that also support the implementation and development of microinsurance. For example, in India, every insurer is required by law to sell a portion of its policies to low-income clients. ${ }^{81}$

Health and non-life insurance schemes in developing countries often run up against problems rooted in legal restrictions. In particular, we find tight regulation schemes ${ }^{16}$ and associated regulation-induced transaction costs in many countries ${ }^{82}$ that affect microinsurers operating as licensed insurers under national insurance law. Microinsurers operating as private for-profit schemes are particularly likely to encounter a strict regulatory framework in many countries. In some cases, for-profit insurance is explicitly prohibited by law or implicitly not permitted by the regulatory process. ${ }^{83}$ Microinsurers not registered with the national insurance regulation authorities bypass this obstacle, but suffer severe limits on their market activity as a consequence. ${ }^{84}$ However, strict regulations do not necessarily imply strict enforcement. The inability of the insurance regulatory authority to enforce its regulations and uncertainty in legal restrictions can result in an erosion of trust in the authority. ${ }^{85}$ Hence, it is an obstacle to market development. Indeed, the microinsurance target population demands the regulatory authority to play an active role in establishing trust in microinsurance institutions. ${ }^{86}$

\section{Discussion of potential solutions}

As shown in the section "Insurability in microinsurance markets", life insurance is least affected by problems of insurability, whereas health and non-life insurance have a high degree of vulnerability to nearly all criteria. We also observe that the degree of violation of insurability criteria is inversely related to market coverage. Life insurance is by far the most successful type of insurance in developing countries; health and nonlife insurance are less common. The fundamental principles reflected by Berliner's insurability criteria are thus of importance also in microinsurance markets. ${ }^{87}$

\footnotetext{
${ }^{80}$ See Ayorinde (2001); Barnett et al. (2008); Churchill (2007); Llanto (2007).

${ }^{81}$ See, for example, Churchill (2007); Roth et al. (2007).

${ }^{82}$ See Drechsler and Jütting (2007); Pauly (2008); Pauly et al. (2006).

${ }^{83}$ See Pauly et al. (2006).

${ }^{84}$ Many microinsurers are probably unable to qualify for an insurance license due to various barriers to entry; see Devadasan et al. (2004b); Dror and Armstrong (2006).

${ }^{85}$ See Barnett and Mahul (2007); Bennett (2004); Dlugolecki (2008); Pannarunothai et al. (2004).

${ }^{86}$ See Schneider (2005).

${ }^{87}$ A more detailed synthesis of results by line of business is available upon request.
} 
Many authors discuss solutions for overcoming the outlined problems. In this section, we provide a synthesis of the solutions found both in the insurance literature as well as in studies on microinsurance. It should be emphasised that the solutions discussed here are not new. What is new is their integrated presentation, systematisation and discussion in this work. The strategies presented in Table 3 can be divided into four categories: capacity building, increasing information flows, employment of disciplinary measures and utilisation of subsidies. The assessment of whether a strategy has an impact on compliance with the insurability criteria is grounded in our understanding of microinsurance markets and the literature we review. The results in Table 3 thus can be interpreted as hypotheses that need further examination. In particular, empirical tests of these hypotheses may be important for a better understanding of microinsurance markets, but these are beyond the scope of this review paper.

\section{Capacity}

The review clearly confirms the need to increase industry capacity, particularly with respect to the size of insurance schemes and their financial capacity. The former can be addressed by increasing merger activity among local insurance schemes and increasing the range of operation; that is, expanding the target market of local microinsurers to a larger area or expanding the range of risks covered. Both options support compliance with the law of large numbers, increase the capacity to bear large losses, and decrease the premium loading that accounts for fluctuations of expected losses. However, growth per se does not create value; efficiency is also crucial. ${ }^{88}$ Furthermore, there is a trade-off between size and proximity to customers. We thus expect that there exists an optimal size for a microinsurer.

Increasing the financial capacity of microinsurers can, however, also be achieved by various means of risk transfer or risk financing, such as reinsurance, index-based reinsurance, derivatives and contingent capital. Dror and Armstrong show in a simulation that reinsurance has high potential to decrease premiums for microinsurance schemes since reinsurance is cheaper than the capital loading for external financing. ${ }^{40}$ Bonnevay et al. illustrate that reinsurance can stabilise a microinsurer's solvency level. ${ }^{89}$ Furthermore, reinsurance provides a means to access professional assistance, such as sharing information, statistical expertise and managerial experience, that would normally not be affordable. ${ }^{90}$ In this respect, the World Bank's efforts to provide reinsurance against drought losses are very promising. ${ }^{91}$ For extremely rare and high losses exceeding the capacity of private insurers, such as some catastrophic risks, the state can act as reinsurer of last resort. ${ }^{92}$

${ }^{88}$ See Biener and Eling (2011) for a discussion of efficiency and microinsurance. Also see Sinha et al. (2007), who report an excessive increase in transaction costs as a result of scaling up an insurance scheme in India.

${ }^{89}$ See Bonnevay et al. (2002).

${ }^{90}$ See Dror (2001).

${ }^{91}$ See World Food Programme (2006).

${ }^{92}$ See Smolka (2006). 


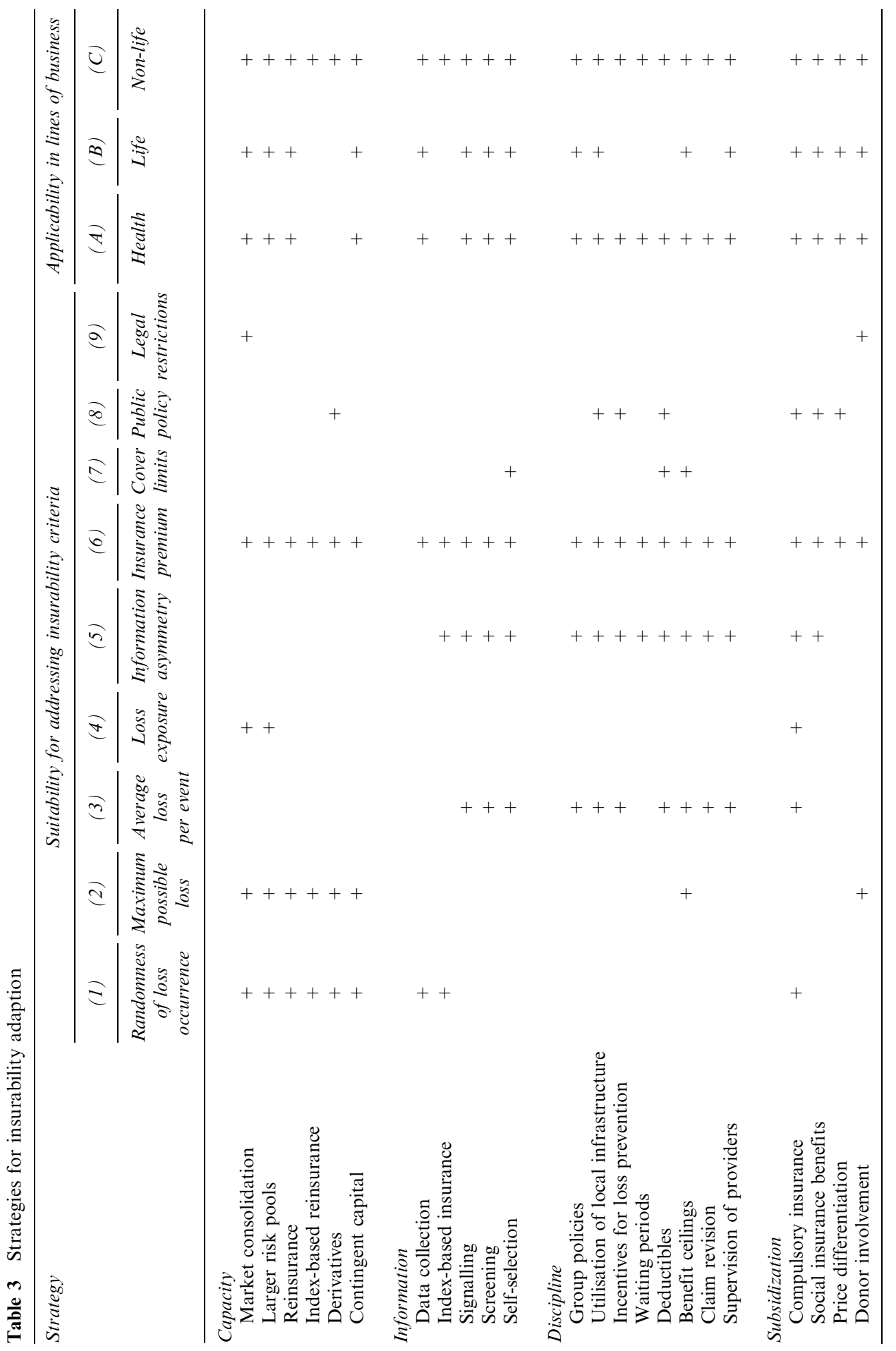




\section{Information and discipline}

As is apparent from the review, information asymmetries have a strong impact on the viability of microinsurance schemes. It is thus imperative to increase the information available for classifying risks, limiting adverse selection and to have disciplinary measures in place that will decrease the probability of moral hazard.

The most obvious way of increasing the informational basis and correctly classifying risks is to encourage data collection efforts that reveal the underlying characteristics of risks; however, data on risks in microinsurance markets is rare. Public institutions, international development agencies and donor organisations could be crucial players in improving this situation and aggregate data from various sources. At the level of individual microinsurance schemes, expert opinions and household surveys may be suitable for providing data on specific risks. ${ }^{93}$ In the absence of information, indexbased insurance can be an attractive substitute for traditional insurance for some risks. If insurance claims are tied to an index, it is not necessary to price individual risks since payouts depend on the respective index. Problems of adverse selection and moral hazard are also eliminated since there is no hidden information and individuals cannot manipulate claims (hidden action). Non-life risks such as agricultural risks are the most suitable for index-based insurance. A drawback is the basis risk of index products, that is, the risk that individual losses significantly deviate from the index loss, a problem that is very hard to communicate to policyholders.

By employing strategies such as signalling and screening, microinsurers can succeed in making insureds provide information about their individual risk that is usually not available and thus limit adverse selection. ${ }^{94}$ These strategies have found wide acceptance in traditional insurance markets and could be an option for microinsurance. Signalling and screening are, however, costly. Thus costs and benefits of such activities need to be carefully considered.

Disciplinary measures that help overcome the imbalance of information between contracting parties are of great importance. Traditional solutions, such as deductibles, ceilings on benefits, waiting periods, vigorous claim investigation, and incentives for loss prevention and reduction (e.g., bonus-malus contracts), might be workable in microinsurance, but there are other mechanisms specifically designed for these markets. Traditional explicit control and enforcement measures are captured in insurance contracts and applied and enforced by the insurance firms themselves; microinsurance-specific disciplinary measures are based on mutual control and enforcement mechanisms in social groups. For example, a group policy is sold to a definite group of people such as a family, a village or the members of an association, which is very different from the traditional insurance policy that insures an individual. Group policies are conducive to mutual monitoring, thus reducing the potential for moral hazard. Adverse selection can also be addressed effectively in this manner, since

\footnotetext{
93 See, for example, Auray and Fonteneau (2002); Dror et al. (2008, 2009b).

${ }^{94}$ Signalling is a means to reduce asymmetric information between potential insureds and insurers by providing a signal of the individual risk type (good, bad) to the insurer. An insurer can apply screening by offering a set of contracts varying in prices and deductibles to induce self-selection of a contract appropriate for the potential insured risk type (see, e.g., Shapira and Venezia, 1999).
} 
it is not only the high-risk individuals of a group that seek insurance coverage but the entire group. ${ }^{95}$

A similar impact might be achieved by utilising local infrastructure, including associations and development aid organisations. Microinsurers that rely on local infrastructure when distributing insurance products, collecting premiums and processing claims have lower transaction costs. ${ }^{65}$ This decentralised approach also allows the insurer to access the high information environment of local communities, which can be beneficial in reducing adverse selection and moral hazard. These measures are thus likely to reduce overall costs and, consequently, insurance premiums. A similar mechanism may be applied at the provider level (e.g., healthcare provider). As the review shows, providers have an incentive to charge higher prices to insured customers and provide poor-quality services, incentives that can only be overcome by supervision and control of provider pricing and service quality.

\section{Subsidisation}

Subsidisation could play a role in achieving affordability of insurance coverage and viability of insurance schemes. Many programmes fail because premium income is not sufficient to cover costs. Subsidised premiums may be a way of decreasing the insured's financial burden and achieving affordability on a large scale. Subsidies may be necessary for only a finite period since increasing size of operation will result in decreased costs and reductions in premium loadings if economies of scale are achieved. Thus, premium reductions will begin to occur "naturally" and subsidies might no longer be necessary. Subsidisation could thus be a means of reaching scale and keeping costs low, especially during the start-up phase. ${ }^{96}$ Indeed, it is very important that subsidies be available only temporarily because an overprovision of subsidies would adversely affect incentives to provide viable products. A further important issue is the level at which subsidies are applied; that is, direct premium subsidisation or indirect subsidisation of premiums through, for example, reinsurance. Subsidies can be relevant at much broader levels and used to stimulate investments in infrastructure, such as health services, improve the microinsurer's capacity and promote the relaxation of market barriers. ${ }^{97}$

Under a compulsory insurance scheme, all individuals of a certain group are obliged to buy an insurance policy covering certain risks. This measure limits adverse selection and enhances risk pooling. ${ }^{92}$ However, as Faure argues, there is a drawback to compulsory insurance when moral hazard is present and insurance is not sufficiently available. $^{98}$

Social insurance is different from compulsory insurance in that premiums are typically collected by the government and often subsidised by taxes. Social insurance can be an effective way of providing affordable insurance coverage and limiting

\footnotetext{
${ }^{95}$ Biener and Eling (2011) find higher efficiency for microinsurers providing group policies.

${ }^{96}$ Dror and Armstrong (2006) show significant differences in capital loadings for external financing between microinsurers of different sizes.

97 See Latortue (2006)

${ }^{98}$ See Faure (2006).
} 
adverse selection when doing so is beneficial from a social policy perspective. Given these characteristics, social insurance can be effective in providing health, unemployment and retirement insurance among others.

A similar balancing can be achieved by microinsurers themselves. Some studies find a potential for price differentiation even within the low-income target audiences of microinsurance schemes. "Higher" low-income individuals could contribute a relatively higher share of total premium income and thus subsidise the "lower" low-income individuals. Furthermore, for health insurance, those insureds living close to healthcare facilities may pay higher premiums than those living further away, since their costs for accessing health services are higher. ${ }^{99}$

Donor organisations are becoming increasingly involved in microinsurance markets. The funds available from donor organisations may have great potential for helping microinsurance schemes reach the necessary scale of operations. This can be achieved by providing capital and knowledge to the microinsurer itself, or to intermediaries and research institutions that advance business knowledge and capacity.

\section{Cooperative strategy as a synthesis of different solutions}

On the basis of the above discussion, we see one integrated approach that has the potential to solve some of the significant problems. We have broadly discussed the trade-off between decentralisation and centralisation in microinsurance markets. For example, decentralisation can overcome information asymmetries; centralisation can lead to more sufficient financial capacity. Transaction cost economists discuss one promising solution in this context-a cooperative architecture. ${ }^{100}$ A cooperative microinsurance architecture could combine the advantages of both centralisation and decentralisation while limiting the disadvantages of each.

The essential idea of the cooperative architecture is to bring together a large number of local organisations under the roof of one parent organisation. The local organisations are the typical microinsurers that distribute insurance products, collect premiums and settle claims locally but cover only small fractions of the market. The parent organisation is owned and operated by these microinsurers, assumes central management functions and realises economies of scale. This architecture makes it possible to address the central issues of capacity-building, information flows, disciplinary measures and subsidies by combining the advantages of a large, centralised organisation with those found in the local organisations that already exist in microinsurance markets. Large, centralised organisations can realise scale economies, diversify risks, have access to reinsurance and other financing sources, and can synthesise management and actuarial knowledge. Governments, reinsurers, large insurers and donor organisations can play a significant role in initiating such schemes. The "roof" section of the cooperative design will need to be monitored very carefully and management needs to be lean, transparent and follow

\footnotetext{
${ }^{99}$ See Ranson et al. (2006); Sinha et al. (2006).

${ }^{100}$ See Mariti and Smiley (1983); Mladovsky and Mossialos (2008); Williamson (1975).
} 
strict rules. In addition to the local institutions, national regulators as well as international institutions could be involved in such monitoring. Local schemes are known, accepted and have access to local infrastructure, exist within a high information environment, and understand the social enforcement mechanisms of local communities. They are able to achieve significantly lower transaction costs for distributing insurance products, collecting premiums and settling claims, and may be able to limit adverse selection and moral hazard.

We are, of course, not the first to think of organising microinsurance activity in a cooperative design. For example, there is Concertation, ${ }^{101}$ a partnership of organisations that promotes mutual health organisations in West Africa. Its objective is to share experiences, competencies and information on development work in West and Central Africa. The cooperative design can thus encompass a range of intensity, from flimsy networks (e.g., exchange of some data) to very intensive collaborations such as joint reinsurance. A large centralised roof for a group of microinsurers might also enhance the self-insurance capabilities. Furthermore, it might serve as a risk carrier itself, for example, by covering the basis risk of index-linked products. ${ }^{102}$

\section{Conclusion}

This paper makes both practical and theoretical contributions to the field of microinsurance. We first aggregate existing knowledge about the problems of insurability in microinsurance markets from a comprehensive set of studies and extract the most significant problems. In a second step, we discuss traditional and innovative solutions to these problems from an insurance economics perspective. To our knowledge, this is the first attempt to systematically analyse the problems in microinsurance markets on an aggregate level based on insurance economics principles. The contribution of this paper is not to present new solutions, but to be a synthesis of the existing knowledge from a variety of fields.

In the literature review, we find that health and non-life insurance are highly prone to problems of insurability, which might explain their relatively low market coverage. In contrast, life insurance has relatively high market coverage and is less affected by insurability problems. These results indicate that fundamental principles regarding the insurability of risks as discussed in Berliner ${ }^{7}$ are of high relevance for microinsurance and that approaches from life microinsurance may provide solutions for other lines of business. A synthesis of the findings reveals that the central issues in the insurability of risks in microinsurance markets stem from non-compliance with actuarial conditions (information asymmetries, small risk pools, insufficient risk evaluation) and widely unaffordable insurance premiums.

${ }^{101}$ For further details, see La Concertation (2010).

${ }^{102}$ While a cooperative microinsurance architecture might be helpful in some cases, it cannot provide a solution to all problems in all lines of business. For example, it is possible that, in some cases, only meso (e.g., reinsurance) or macro level (e.g., legislation, regulation) solutions are possible in the long run and no microinsurance at all. More empirical studies are needed to identify the optimal level to provide most efficient solutions. 
We discuss potential solutions to these problems and systematise these in the four categories capacity-building, increase of information flows, employment of disciplinary measures and utilisation of subsidies. We discuss a cooperative architecture of microinsurance schemes that provides an integrated solution to some of the problems in this market. Setting up microinsurers as cooperatives may be a way of combining the advantages of large institutions (e.g., diversification, economies of scale and access to reinsurance) with those of local organisations (e.g., low transaction costs, access to information and social enforcement mechanisms).

We hope that this paper encourages other researchers to conduct more work on microinsurance. A significant need for future research can be derived from the discussion provided in this paper. The first aspect is the need to empirically investigate the hypotheses developed in Table 3, especially the effectiveness of cooperatives and other solutions at the micro, meso and macro level. A second aspect might be to expand and redefine the criteria catalogue by Berliner to more closely meet the special environment in which microinsurance operates.

Discrimination between insurable and uninsurable risks basically constitutes a sound underwriting policy that assures the viable and sustainable provision of insurance coverage. Microinsurance markets today lack sound underwriting practices and need to focus more on insurable risks and strategies that have the potential to expand the limits of insurability.

\section{Acknowledgements}

We thank two anonymous reviewers, Christian Kraus, Martin Müller, Andreas Niemeyer, Jan-Philipp Schmidt, Joan Schmit, Yi Yao, and the participants of the World Risk and Insurance Economics Congress 2010 in Singapore for their helpful questions and comments.

\section{References}

Acharya, A. and Ranson, M.K. (2005) 'Health care financing for the poor: Community-based health insurance schemes in Gujarat', Economic and Political Weekly 40(38): 4141-4150.

Arena, M. (2008) 'Does insurance market activity promote economic growth? A cross-country study for industrialized and developing countries', Journal of Risk and Insurance 75(4): 921-946.

Asfaw, A. and Jütting, J.P. (2007) 'The role of health insurance in poverty reduction: Empirical evidence from Senegal', International Journal of Public Administration 30(8): 835-858.

Atim, C. (1999) 'Social movements and health insurance: A critical evaluation of voluntary, non-profit insurance schemes with case studies from Ghana and Cameroon', Social Science \& Medicine 48(7): 881-896.

Auray, J.P. and Fonteneau, R. (2002) 'Local consensus and estimates of medical risk', in D.M. Dror and A.S. Preker (eds.) Social Reinsurance: A New Approach to Sustainable Community Health Financing, Washington, DC: World Bank, pp. 187-201.

Ayorinde, R.O. (2001) 'Insurance-fund investment regulation in Nigeria', Journal of Insurance Regulation 20(2): 195-206.

Barnett, B.J., Barrett, C.B. and Skees, J.R. (2008) 'Poverty traps and index-based risk transfer products', World Development 36(10): 1766-1785.

Barnett, B.J. and Mahul, O. (2007) 'Weather index insurance for agriculture and rural areas in lower-income countries', American Journal of Agricultural Economics 89(5): 1241-1247.

Bennett, S. (2004) 'The role of community-based health insurance within the health care financing system: A framework for analysis', Health Policy and Planning 19(3): 147-158. 
Berliner, B. (1982) Limits of Insurability of Risks, Englewood Cliffs, NJ: Prentice-Hall.

Biener, C. and Eling, M. (2011) 'The performance of microinsurance programs: A data envelopment analysis', Journal of Risk and Insurance 78(1): 83-115.

Bonnevay, S., Dror, D.M., Duru, G. and Lamure, M. (2002) 'A model of microinsurance and reinsurance', in D.M. Dror and A.S. Preker (eds.) Social Reinsurance: A New Approach to Sustainable Community Health Financing, Washington, DC: World Bank, pp. 153-186.

Bryant, J. and Prohmmo, A. (2002) 'Equal contributions and unequal risks in a North-East Thai village funeral society', Journal of Development Studies 38(3): 63-75.

Carrin, G. (2002) 'Social health insurance in developing countries: A continuing challenge', International Social Security Review 55(2): 57-69.

Carrin, G., Waelkens, M.-P. and Criel, B. (2005) 'Community-based health insurance in developing countries: A study of its contribution to the performance of health financing systems', Tropical Medicine \& International Health 10(8): 799-811.

Chankova, S., Sulzbach, S. and Diop, F. (2008) 'Impact of mutual health organizations: Evidence from West Africa', Health Policy and Planning 23(4): 264-276.

Chantarat, S., Barrett, C.B., Mude, A.G. and Turvey, C.G. (2007) 'Using weather index insurance to improve drought response for famine prevention', American Journal of Agricultural Economics 89(5): 1262-1268.

Charpentier, A. (2008) 'Insurability of climate risks', The Geneva Papers on Risk and Insurance-Issues and Practice 33(1): 91-109.

Churchill, C. (2002) 'Trying to understand the demand for microinsurance', Journal of International Development 14(3): 381-387.

Churchill, C. (2007) 'Insuring the low-income market: Challenges and solutions for commercial insurers', The Geneva Papers on Risk and Insurance-Issues and Practice 32(3): 401-412.

Churchill, C., Liber, D., McCord, M.J. and Roth, J. (2003) Making Insurance Work for Microfinance Institutions: A Technical Guide to Developing and Delivering Microinsurance, Geneva: International Labour Organization.

Cohen, M., McCord, M.J. and Sebstad, J. (2005) 'Reducing vulnerability: Demand for and supply of microinsurance in East Africa', Journal of International Development 17(3): 319-325.

Cohen, M. and Sebstad, J. (2005) 'Reducing vulnerability: The demand for microinsurance', Journal of International Development 17(3): 397-474.

Criel, B., van der Stuyft, P. and van Lerberghe, W. (1999) 'The Bwamanda hospital insurance scheme: Effective for whom? A study of its impact on hospital utilization patterns', Social Science \& Medicine 48(7): 897-911.

Criel, B. and Waelkens, M.P. (2003) 'Declining subscriptions to the Maliando mutual health organisation in Guinea-Conakry (West Africa): What is going wrong?' Social Science \& Medicine 57(7): 1205-1219.

de Allegri, M., Sanon, M., Bridges, J. and Sauerborn, R. (2006) 'Understanding consumers' preferences and decision to enrol in community-based health insurance in rural West Africa', Health Policy 76(1): 58-71.

Dekker, M. and Wilms, A. (2010) 'Health insurance and other risk-coping strategies in Uganda: The case of Microcare Insurance Ltd', World Development 38(3): 369-378.

Dercon, S., Weerdt, J.de, Bold, T. and Pankhurst, A. (2006) 'Group-based funeral insurance in Ethiopia and Tanzania', World Development 34(4): 685-703.

Desmet, M., Chowdhury, A.Q. and Islam, M.K. (1999) 'The potential for social mobilisation in Bangladesh: The organisation and functioning of two health insurance schemes', Social Science \& Medicine 48(7): 925-938.

Devadasan, N., Criel, B., van Damme, W., Ranson, K. and van der Stuyft, P. (2007) 'Indian community health insurance schemes provide partial protection against catastrophic health expenditure', $B M C$ Health Services Research 7(43): 1-11.

Devadasan, N., Manoharan, S., Menon, N., Menon, S., Thekaekara, M. and Thekaekara, S. (2004a) 'ACCORD community health insurance: Increasing access to hospital care', Economic and Political Weekly 39(28): 3189-3194.

Devadasan, N., Ranson, K., van Damme, W., Acharya, A. and Criel, B. (2006) 'The landscape of community health insurance in India: An overview based on 10 case studies', Health Policy 78(2-3): 224-234. 
100

Devadasan, N., Ranson, K., van Damme, W. and Criel, B. (2004b) 'Community health insurance in India: An overview', Economic and Political Weekly 39(28): 3179-3183.

Dlugolecki, A. (2008) 'Climate change and the insurance sector', The Geneva Papers on Risk and InsuranceIssues and Practice 33(1): 71-90.

Doherty, N.A. (1991) 'The design of insurance contracts when liability rules are unstable', Journal of Risk and Insurance 58(2): 227-246.

Dong, H., Bogg, L., Wang, K., Rehnberg, C. and Diwan, V. (1999) 'A description of outpatient drug use in rural China: Evidence of differences due to insurance coverage', International Journal of Health Planning and Management 14(1): 41-56.

Dong, H., Mugisha, F., Gbangou, A., Kouyate, B. and Sauerborn, R. (2004) 'The feasibility of communitybased health insurance in Burkina Faso', Health Policy 69(1): 45-53.

Drechsler, D. and Jütting, J.P. (2007) 'Different countries, different needs: The role of private health insurance in developing countries', Journal of Health Politics, Policy and Law 32(3): 497-534.

Dror, D.M. (2001) 'Reinsurance of health insurance for the informal sector', Bulletin of the World Health Organization 79(7): 672-678.

Dror, D.M. and Armstrong, J. (2006) 'Do micro health insurance units need capital or reinsurance? A simulated exercise to examine different alternatives', The Geneva Papers on Risk and Insurance-Issues and Practice 31(4): 739-761.

Dror, D.M. and Jacquier, C. (1999) 'Micro-insurance: Extending health insurance to the excluded', International Social Security Review 52(1): 71-97.

Dror, D.M., Koren, R., Ost, A., Binnendijk, E., Vellakkal, S. and Danis, M. (2007) 'Health insurance benefit packages prioritized by low-income clients in India: Three criteria to estimate effectiveness of choice', Social Science \& Medicine 64(4): 884-896.

Dror, D.M., Radermacher, R., Khadilkar, S.B., Schout, P., Hay, F.X., Singh, A. and Koren, R. (2009a) 'Microinsurance: Innovations in low-cost health insurance', Health Affairs 28(6): 1788-1798.

Dror, D.M., Soriano, E.S., Lorenzo, M.E., Sarol, J.J.N., Azcuna, R.S. and Koren, R. (2005) 'Field based evidence of enhanced healthcare utilization among persons insured by micro health insurance units in Philippines', Health Policy 73(3): 263-271.

Dror, D.M., van Putten-Rademaker, O. and Koren, R. (2008) 'Cost of illness: Evidence from a study in five resource-poor locations in India', Indian Journal of Medical Research 127(4): 347-361.

Dror, D.M., van Putten-Rademaker, O. and Koren, R. (2009b) 'Incidence of illness among resource-poor households: Evidence from five locations in India', Indian Journal of Medical Research 130(2): $146-154$.

Ekman, B. (2004) 'Community-based health insurance in low-income countries: A systematic review of the evidence', Health Policy and Planning 19(5): 249-270.

Ekman, B. (2007) 'Catastrophic health payments and health insurance: Some counterintuitive evidence from one low-income country', Health Policy 83(2-3): 304-313.

Ensor, T. (1999) 'Developing health insurance in transitional Asia', Social Science \& Medicine 48: 871-879.

Faure, M.G. (2006) 'Economic criteria for compulsory insurance', The Geneva Papers on Risk and Insurance-Issues and Practice 31(1): 149-168.

Francisco, H.A. (2008) 'Adaptation to climate change: Needs and opportunities in Southeast Asia', $A S E A N$ Economic Bulletin 25(1): 7-19.

Giesbert, L., Steiner, S. and Bendig, M. (2011) 'Participation in micro life insurance and the use of other financial services in Ghana', Journal of Risk and Insurance 78(1): 7-35.

Giné, X., Townsend, R. and Vickery, J. (2007) 'Statistical analysis of rainfall insurance payouts in Southern India', American Journal of Agricultural Economics 89(5): 1248-1254.

Hamid, S.A., Roberts, J. and Mosley, P. (2011) 'Can micro health insurance reduce poverty? Evidence from Bangladesh', Journal of Risk and Insurance 78(1): 57-82.

Herweijer, C., Ranger, N. and Ward, R.E.T. (2009) 'Adaptation to climate change: Threats and opportunities for the insurance industry', The Geneva Papers on Risk and Insurance-Issues and Practice 34(3): 360-380.

Ito, S. and Kono, H. (2010) 'Why is the take-up of microinsurance so low? Evidence from a health insurance scheme in India', Developing Economies 48(1): 74-101. 
Jaffee, D.M. and Russell, T. (1997) 'Catastrophe insurance, capital markets, and uninsurable risks', Journal of Risk and Insurance 64(2): 205-230.

Janssen, J. (2000) 'Implementing the Kyoto mechanisms: Potential contributions by banks and insurance companies', The Geneva Papers on Risk and Insurance - Issues and Practice 25(4): 602-618.

Jowett, M., Contoyannis, P. and Vinh, N.D. (2003) 'The impact of public voluntary health insurance on private health expenditures in Vietnam', Social Science \& Medicine 56(2): 333-342.

Jowett, M., Deolalikar, A. and Martinsson, P. (2004) 'Health insurance and treatment seeking behaviour: Evidence from a low-income country', Health Economics 13(9): 845-857.

Jütting, J.P. (2004) 'Do community-based health insurance schemes improve poor people's access to health care? Evidence from rural Senegal', World Development 32(2): 273-288.

Karten, W.T. (1997) 'How to expand the limits of insurability', The Geneva Papers on Risk and Insurance-Issues and Practice 22(4): 515-522.

Kiwara, A.D. (2007) 'Group premiums in micro health insurance experiences from Tanzania', East African Journal of Public Health 4(1): 28-32.

Kunreuther, H. and Michel-Kerjan, E. (2004) Insurability of (Mega)-Terrorism Risk: Challenges and Perspectives, Report prepared for the OECD Task Force on Terrorism Insurance, Paris.

La Concertation (2010) from: www.social-protection.org/gimi/gess/showtheme.do?tid=2445, accessed 15 October 2010.

Latortue, A. (2006) 'The role of donors', in C. Churchill (ed.) Protecting the Poor: A Microinsurance Compendium, Geneva: International Labour Organization, pp. 470-487.

Levin, T. and Reinhard, D. (2007) Microinsurance Aspects in Agriculture, Munich Re Foundation Discussion Paper, Munich.

Linnerooth-Bayer, J. and Amendola, A. (2000) 'Global change, natural disasters and loss-sharing: Issues of efficiency and equity', The Geneva Papers on Risk and Insurance-Issues and Practice 25(2): 203-219.

Linnerooth-Bayer, J. and Mechler, R. (2006) 'Insurance for assisting adaptation to climate change in developing countries: A proposed strategy', Climate Policy 6(6): 621-636.

Linnerooth-Bayer, J., Mechler, R. and Pflug, G. (2005) 'Refocusing disaster aid', Science 309(5737): 1044-1046.

Linnerooth-Bayer, J., Warner, K., Bals, C., Höppe, P., Burton, I., Loster, T. and Haas, A. (2009) 'Insurance, developing countries and climate change', The Geneva Papers on Risk and Insurance-Issues and Practice 34(3): $381-400$.

Llanto, G.M. (2007) 'Policy and regulatory issues and challenges in microinsurance: A Philippine case', Philippine Journal of Development 34(1): 61-86.

Lloyd's and Microinsurance Centre (2009) Insurance in Developing Countries: Exploring Opportunities in Microinsurance, $360^{\circ}$ Risk Insight Report, London.

Mariti, P. and Smiley, R.H. (1983) 'Co-operative agreements and the organization of industry', Journal of Industrial Economics 31(4): 437-451.

McCord, M.J. (2001) 'Health care microinsurance-Case studies from Uganda, Tanzania, India and Cambodia', Small Enterprise Development 12(1): 25-38.

McCord, M.J. (2007) 'Supplying health microinsurance: Lessons from East Africa', International Journal of Public Administration 30(8-9): 737-764.

McCord, M.J. and Osinde, S. (2005) 'Reducing vulnerability: The supply of health microinsurance in East Africa', Journal of International Development 17(3): 327-381.

Meze-Hausken, E., Patt, A. and Fritz, S. (2009) 'Reducing climate risk for micro-insurance providers in Africa: A case study of Ethiopia', Global Environmental Change 19(1): 66-73.

Mills, E. (2005) 'Insurance in a climate of change', Science 309(5737): 1040-1044.

Miranda, M.J. and Glauber, J.W. (1997) 'Systematic risk, reinsurance, and the failure of crop insurance markets', American Journal of Agricultural Economics 79(1): 206-215.

Mladovsky, P. and Mossialos, E. (2008) 'A conceptual framework for community-based health insurance in low-income countries: Social capital and economic development', World Development 36(4): 590-607.

Morduch, J. (2006) 'Microinsurance: The next revolution?', in A.V. Banerjee, R. Bénabou and D. Mookherjee (eds.) Understanding Poverty, New York: Oxford University Press, pp. 337-355. 
Msuya, J.M., Jütting, J.P. and Asfaw, A. (2007) 'Impact of community health funds on the access to health care: Empirical evidence from rural Tanzania', International Journal of Public Administration 30(8): 813-833.

Murgai, R., Winters, P., Sadoulet, E. and Janvry, A.de (2002) 'Localized and incomplete mutual insurance', Journal of Development Economics 67(2): 245-274.

Nierhaus, F. (1986) 'A strategic approach to insurability of risks', The Geneva Papers on Risk and Insurance-Issues and Practice 11(2): 83-90.

Nyman, J.A. (1999) 'The value of health insurance: The access motive', Journal of Health Economics 18(2): $141-152$.

Obermann, K., Jowett, M.R., Alcantara, M.O.O., Banzon, E.P. and Bodart, C. (2006) 'Social health insurance in a developing country: The case of the Philippines', Social Science \& Medicine 62(12): $3177-3185$.

Pannarunothai, S., Patmasiriwat, D. and Srithamrongsawat, S. (2004) 'Universal health coverage in Thailand: Ideas for reform and policy struggling', Health Policy 68(1): 17-30.

Pannarunothai, S., Srithamrongsawat, S., Kongpan, M. and Patchanee, T. (2000) 'Financing reforms for the Thai health card scheme', Health Policy and Planning 15(3): 303-311.

Patt, A., Suarez, P. and Hess, U. (2010) 'How do small-holder farmers understand insurance, and how much do they want it? Evidence from Africa', Global Environmental Change 20(1): 153-161.

Pauly, M.V. (2008) 'The evolution of health insurance in India and China', Health Affairs 11(4): 1016-1019.

Pauly, M.V., Zweifel, P., Scheffler, R.M., Preker, A.S. and Bassett, M. (2006) 'Private health insurance in developing countries', Health Affairs 25(2): 369-379.

Poletti, T., Balabanova, D., Ghazaryan, O., Kocharyan, H., Hakobyan, M., Arakelyan, K. and Normand, C. (2007) 'The desirability and feasibility of scaling up community health insurance in low-income settings - Lessons from Armenia', Social Science \& Medicine 64(3): 509-520.

Polonsky, J., Balabanova, D., McPake, B., Poletti, T., Vyas, S., Ghazaryan, O. and Yanni, M.K. (2009) 'Equity in community health insurance schemes: Evidence and lessons from Armenia', Health Policy and Planning 24(3): 209-216.

Radermacher, R., Ashok, S., Zabel, K. and Dror, I. (2009) What do we know about the impact of microinsurance, paper presented at the Microinsurance Conference 2009, New Delhi.

Ranson, M.K. and John, K.R. (2002) 'Quality of hysterectomy care in rural Gujarat: The role of community-based health insurance', Reproductive Health Matters 10(20): 70-81.

Ranson, M.K., Sinha, T., Chatterjee, M., Acharya, A., Bhavsar, A., Morris, S.S. and Mills, A.J. (2006) 'Making health insurance work for the poor: Learning from the self-employed women's association's (SEWA) community-based health insurance scheme in India', Social Science \& Medicine 62(3): 707-720.

Ranson, M.K., Sinha, T., Chatterjee, M., Gandhi, F., Jayswal, R., Patel, F., Morris, S.S. and Mills, A.J. (2007) 'Equitable utilisation of Indian community based health insurance scheme among its rural membership: Cluster randomised controlled trial', British Medical Journal 334(7607): 1-9.

Roth, J., McCord, M.J. and Liber, D. (2007) The Landscape of Microinsurance in the World's 100 Poorest Countries, Report of the Microinsurance Centre, Appleton.

Sapelli, C. and Vial, B. (2003) 'Self-selection and moral hazard in Chilean health insurance', Journal of Health Economics 22(3): 459-476.

Schmit, J.T. (1986) 'A new view of the requisites of insurability', The Journal of Risk and Insurance 53(2): $320-329$.

Schneider, P. (2005) 'Trust in micro-health insurance: An exploratory study in Rwanda', Social Science \& Medicine 61(7): 1430-1438.

Schneider, P. and Hanson, K. (2006) 'Horizontal equity in utilisation of care and fairness of health financing: A comparison of micro-health insurance and user fees in Rwanda', Health Economics 15(1): 19-31.

Schneider, P. and Hanson, K. (2007) 'The impact of micro health insurance on Rwandan health centre costs', Health Policy and Planning 22(1): 40-48.

Sepehri, A., Sarma, S. and Simpson, W. (2006) 'Does non-profit health insurance reduce financial burden? Evidence from the Vietnam living standards survey panel', Health Economics 15(6): 603-616.

Shapira, Z. and Venezia, I. (1999) 'Experimental tests of self-selection and screening in insurance decisions', The Geneva Papers on Risk and Insurance Theory 24(2): 139-158. 
Sinha, T., Ranson, M.K., Chatterjee, M., Acharya, A. and Mills, A.J. (2006) 'Barriers to accessing benefits in a community-based insurance scheme: Lessons learnt from SEWA insurance', Health Policy and Planning 21(2): 132-142.

Sinha, T., Ranson, M.K. and Mills, A.J. (2007) 'Protecting the poor? The distributional impact of a bundled insurance scheme', World Development 35(8): 1404-1421.

Smolka, A. (2006) 'Natural disasters and the challenge of extreme events: Risk management from an insurance perspective', Philosophical Transactions: Mathematical, Physical and Engineering Sciences 364(1845): 2147-2165.

Supakankunti, S. (2000) 'Future prospects of voluntary health insurance in Thailand', Health Policy and Planning 15(1): 85-94.

Torkestani, M.S. and Ahadi, P. (2008) 'Readiness assessment of Islamic micro-finance institution to implement micro-insurance concept (case of Iran)', International Journal of Islamic and Middle Eastern Finance and Management 1(3): 249-261.

Vaté, M. and Dror, D.M. (2002) 'To insure or not to insure? Reflections on the limits of insurability', in D.M. Dror and A.S. Preker (eds.) Social Reinsurance: A New Approach to Sustainable Community Health Financing, Washington, DC: World Bank, pp. 125-148.

Vermaat, A.J. (1995) 'Uninsurability: A growing problem', The Geneva Papers on Risk and Insurance-Issues and Practice 20(4): 446-453.

Wagstaff, A. and Lindelow, M. (2008) 'Can insurance increase financial risk? The curious case of health insurance in China', Journal of Health Economics 27(4): 990-1005.

Wagstaff, A., Lindelow, M., Jun, G., Ling, X. and Juncheng, Q. (2009) 'Extending health insurance to the rural population: An impact evaluation of China's new cooperative medical scheme', Journal of Health Economics 28(1): 1-19.

Wang, H., Zhang, L., Yip, W. and Hsiao, W. (2006) 'Adverse selection in a voluntary rural mutual health care health insurance scheme in China', Social Science \& Medicine 63(5): 1236-1245.

Wiesmann, D. and Jütting, J.P. (2000) 'The emerging movement of community based health insurance in Sub-Saharan Africa', Africa Spectrum 35(2): 193-210.

Wiesmann, D. and Jütting, J.P. (2001) 'Determinants of viable health insurance schemes in rural Sub-Saharan Africa', Quarterly Journal of International Agriculture 40(4): 361-378.

Williamson, O.E. (1975) Markets and Hierarchies: Analysis and Antitrust Implications, New York: Free Press.

World Food Programme (2006) 'World's First Humanitarian Insurance Policy Issued', from: http:// www.wfp.org/node/598, accessed 11 October 2010.

Yanli, Z. (2009) 'An introduction to the development and regulation of agricultural insurance in China', The Geneva Papers on Risk and Insurance-Issues and Practice 34(1): 78-84.

Zhang, L., Wang, H., Wang, L. and Hsiao, W. (2006) 'Social capital and farmer's willingness-to-join a newly established community-based health insurance in rural China', Health Policy 76(2): 233-242.

\section{About the Authors}

Christian Biener is a doctoral candidate and research assistant at the University of Ulm, Germany, affiliated to the Institute of Insurance Science. He studied business administration at Goethe University, Frankfurt, Germany, majoring in finance.

Martin Eling is a Professor for Insurance and Director of the Institute of Insurance Science at the University of Ulm. He received his doctoral degree in 2005 from the University of Münster and his postdoctoral lecture qualification (Habilitation) in 2009 from the University of St. Gallen. In 2008, he has been Visiting Professor at the University of Wisconsin - Madison. His main research interests are asset management, risk management, regulation, and empirical aspects of finance and insurance 


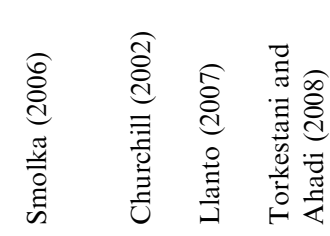

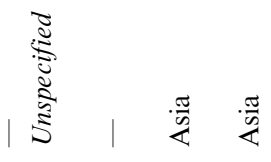

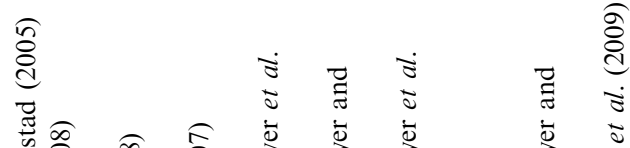

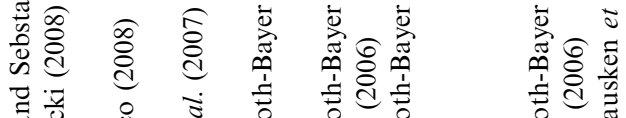

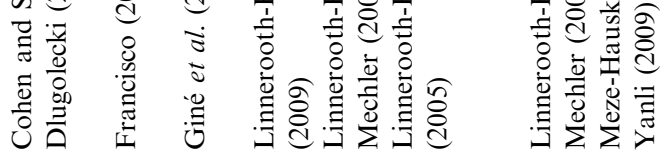

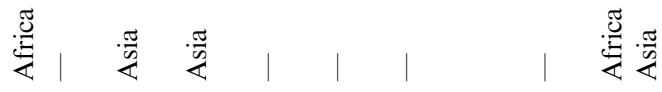

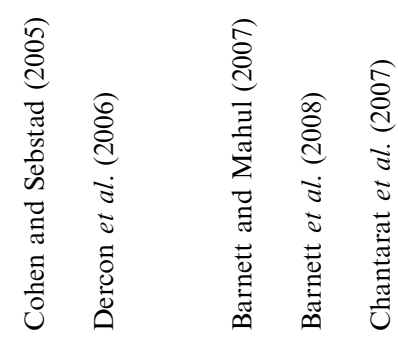

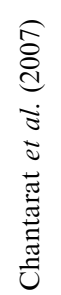

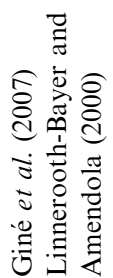

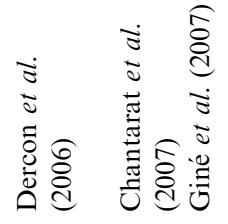

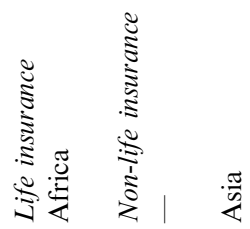

ڤ્ڤ

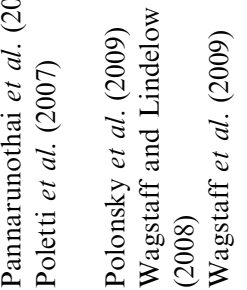

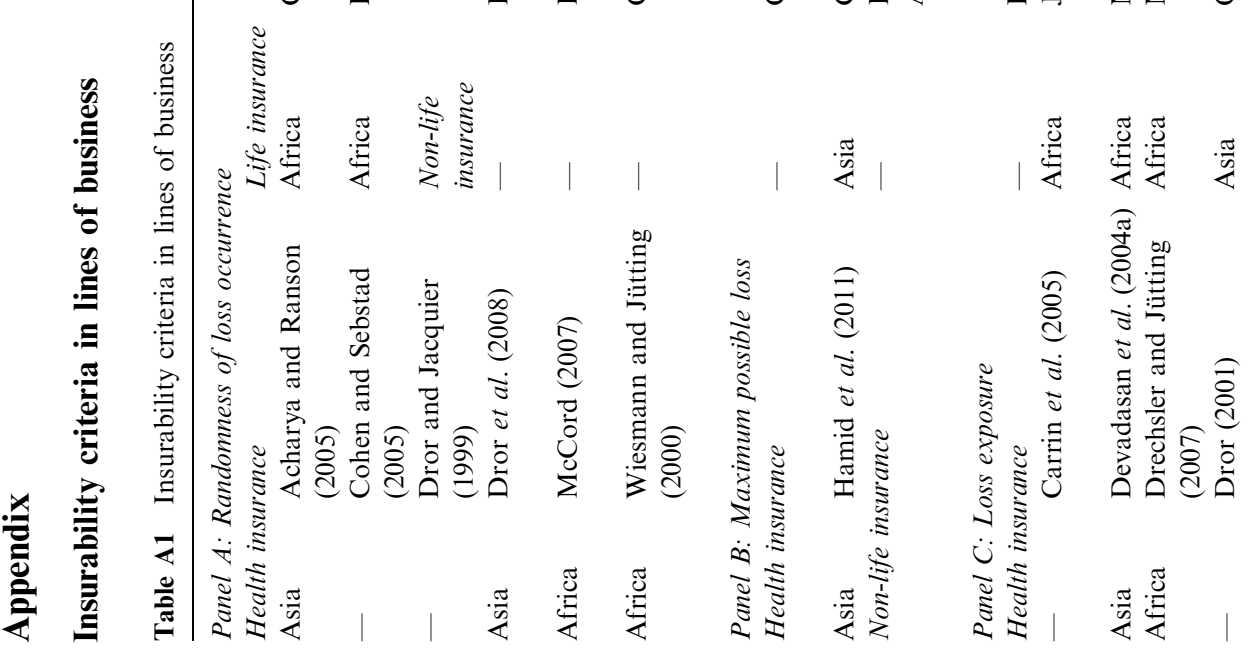




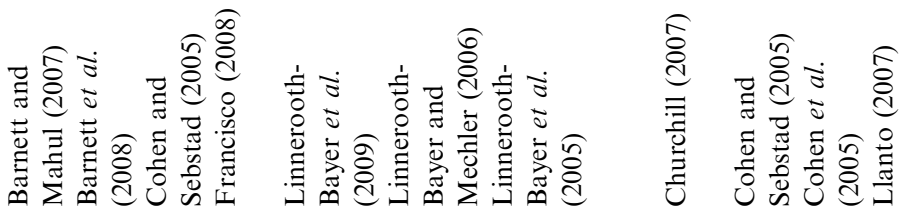

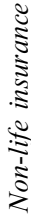

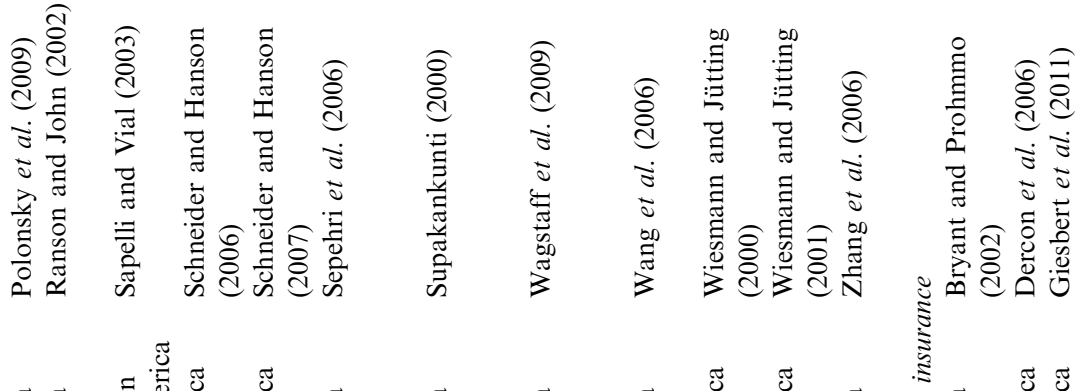

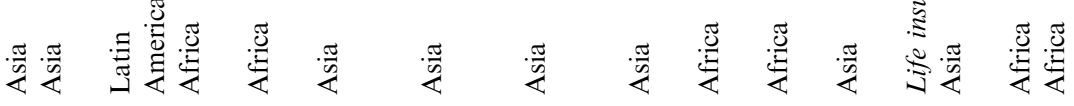

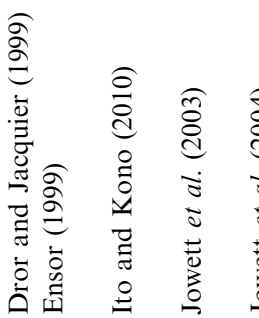

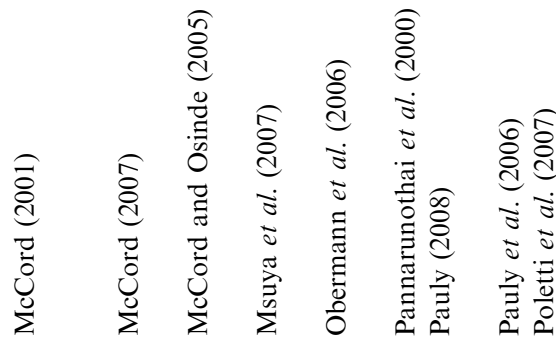

$\frac{\pi}{\sqrt{n}}$

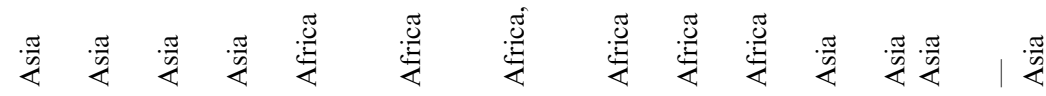

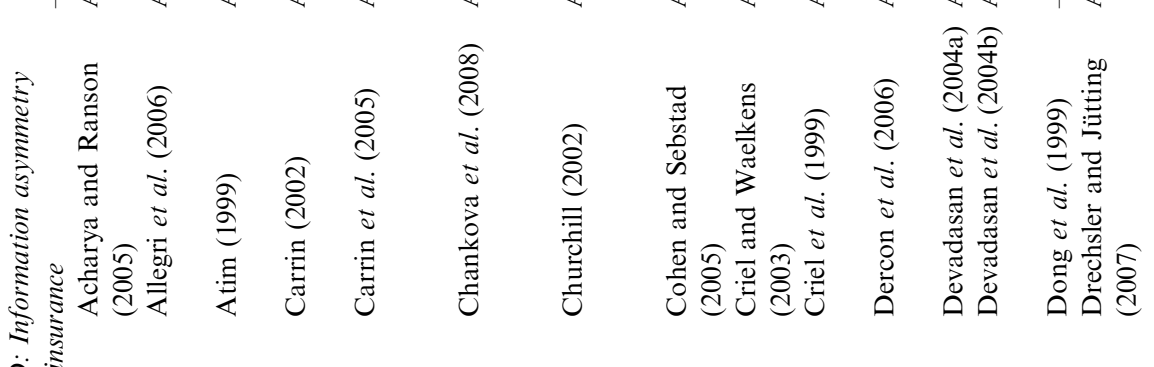

$\ddot{\theta} \div$

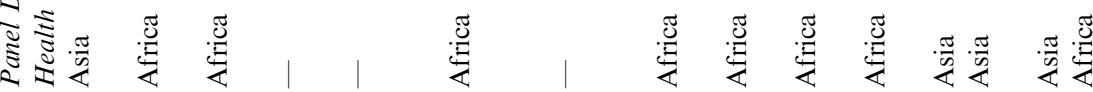




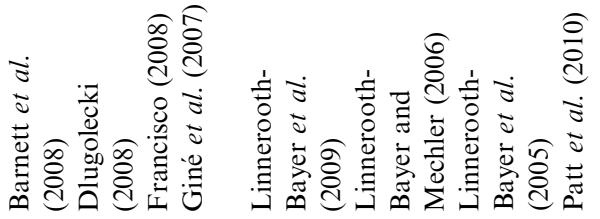

¿

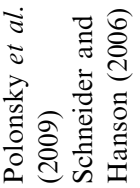

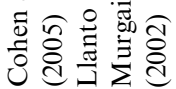

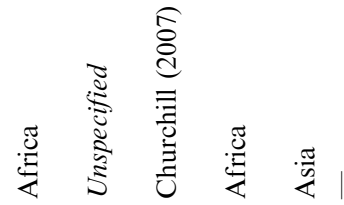

采 这

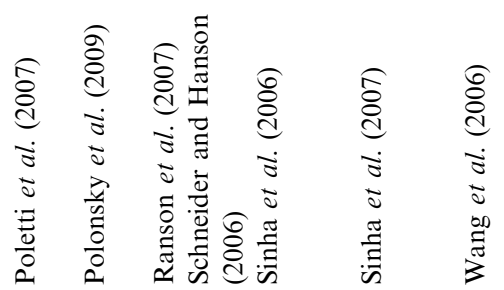

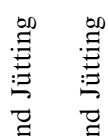

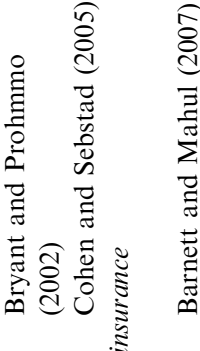

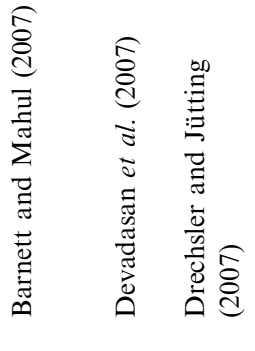

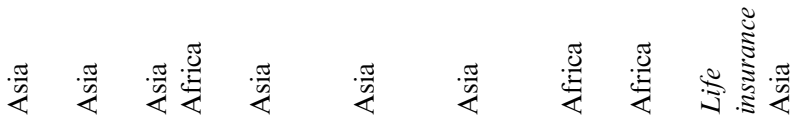

¿্․

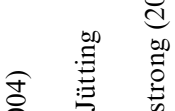

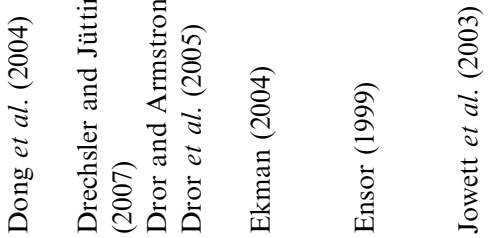

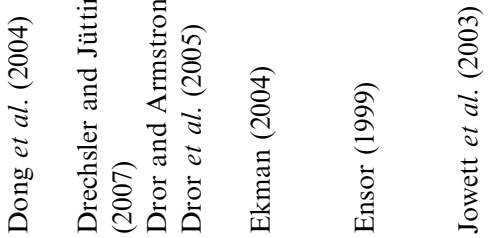

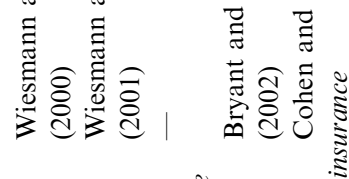

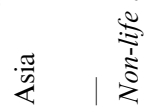

要

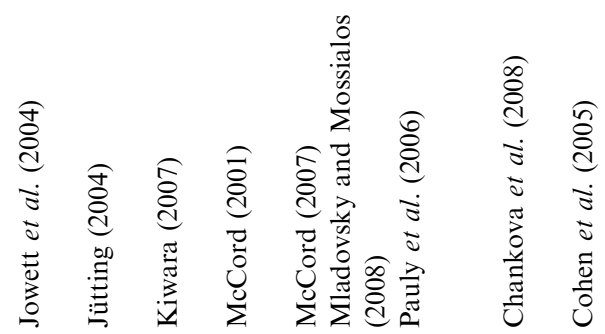

$\frac{\pi}{2}$

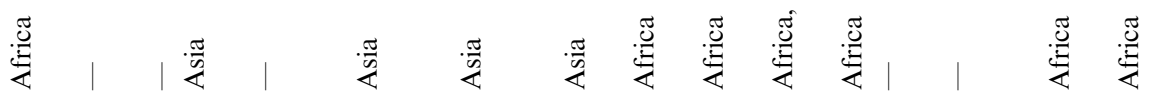

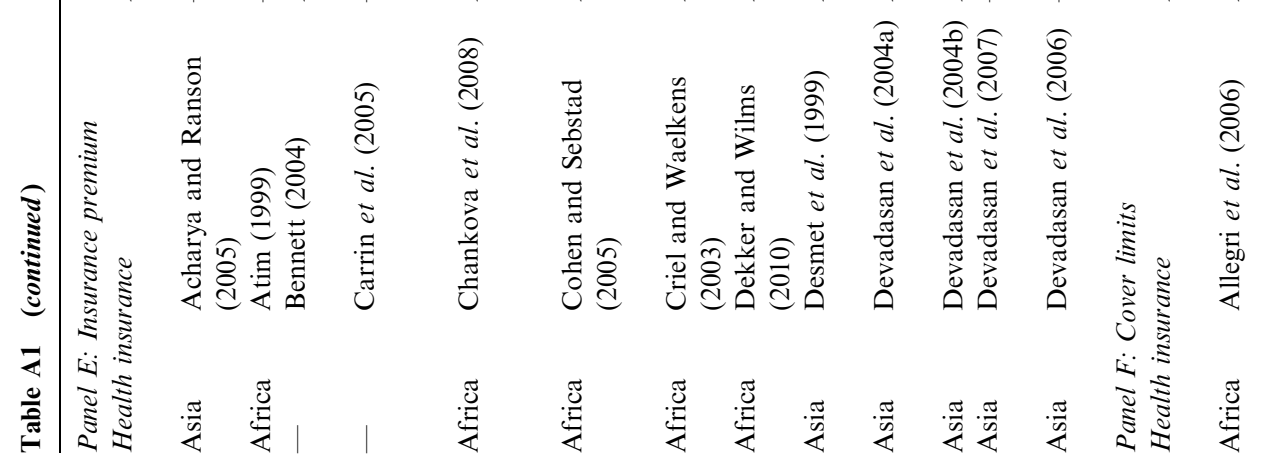

先

$\frac{\pi}{2} \quad \frac{\pi}{2}$ 


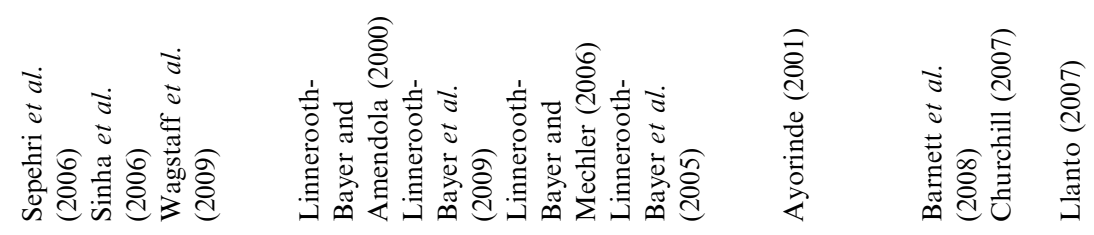

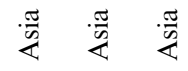

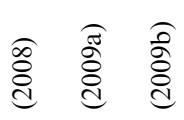

उ

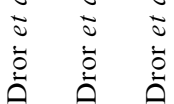

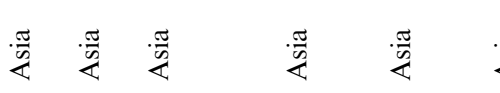

令

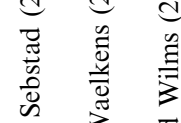

吾

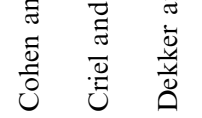

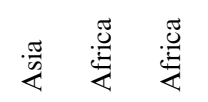

要管

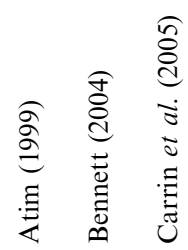

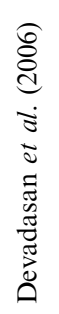

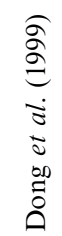

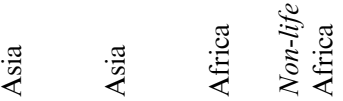

芯

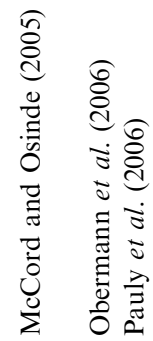

$\frac{\pi}{2}$

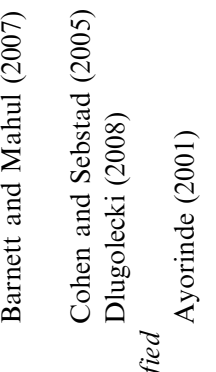

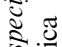

107 